Hernández Pérez, M. S., López Padilla, J. A. y Jover Maestre, F. J. (2019): “Estratigrafía y radiocarbono: la tumba 1 y la cronología de la ocupación argárica del Tabayá (Aspe, Alicante)", Spal 28.1: 35-55. DOI: http://dx.doi.org/10.12795/spal.2019.i28.02

\title{
ESTRATIGRAFÍA Y RADIOCARBONO: LA TUMBA 1 Y LA CRONOLOGÍA DE LA OCUPACIÓN ARGÁRICA DEL TABAYÁ (ASPE, ALICANTE)
}

\section{ESTRATRIGRAPHY AND RADIOCARBON DATING: THE TOMB 1 AND THE CHRONOLOGY OF THE ARGARIC SITE OCCUPATION OF TABAYÁ (ASPE, ALICANTE)}

\author{
MAURO S. HERNÁNDEZ PÉREZ \\ Departamento de Prehistoria, Arqueología, Ha Antigua, Filología Griega y Filología Latina. Universidad de Alicante \\ Carretera de San Vicente s/n 03690 San Vicente del Raspeig \\ Correo-e: mauro.hernandez@ua.es. (iD) https://orcid.org/0000-0001-8225-4730 \\ JUAN A. LÓPEZ PADILLA \\ Museo Arqueológico Provincial de Alicante. MARQ. Plaza Gómez Ulla, 13. 03013 Alicante \\ Correo-e: japadi@diputacionalicante.es. (D) https://orcid.org/0000-0002-1506-4731 \\ FRANCISCO JAVIER JOVER MAESTRE \\ Instituto Universitario de Investigación en Arqueología y Patrimonio Histórico INAPH. Universidad de Alicante \\ Carretera de San Vicente s/n 03690 San Vicente del Raspeig. \\ Correo-e: javier.jover@ua.es. (iD) https://orcid.org/0000-0001-5213-236
}

Resumen: El descubrimiento e implementación, a partir de mediados del siglo XX, de la datación radiocarbónica constituyó un hito trascendental para la investigación arqueológica. Su desarrollo técnico a lo largo de las últimas décadas ha ampliado, hasta extremos no hace mucho difíciles de imaginar, las posibilidades de abordar problemas cronológicos de carácter histórico a partir del análisis de contextos arqueológicos. Sin embargo, durante este tiempo también se ha comprobado que, para estos propósitos, la utilidad de las fechas de ${ }^{14} \mathrm{C}$ no solo depende de la fiabilidad de los contextos de procedencia de las muestras datadas, sino que la aceptación de su validez como dato arqueológico también dependerá de su coherencia con el resto de la información disponible. En este trabajo presentamos una valoración crítica de las dataciones radiocarbónicas obtenidas hasta este momento en el yacimiento del Tabayá (Aspe, Alicante), correspondientes a su ocupación argárica, y se exponen los argumentos que han llevado a considerar como inválidas dos de ellas, tomadas de la tumba 1 , atendiendo a las inconsistencias que muestran tanto en relación con la estratigrafía registrada como con respecto a las dataciones obtenidas para la tumba 3 . Por último, se propone una cronología relativa para el conjunto de la tumba 1 del Tabayá a partir de las fechas radiocarbónicas de los niveles infrapuestos a esta y de la tumba 3, así como de los datos estratigráficos que ponen en relación ambas sepulturas. Palabras clave: Radiocarbono, Edad del Bronce, El Argar, enterramientos, estratigrafía.
Abstract: The discovery and implementation of radiocarbon dating, from the middle of the 20th century, was a transcendental milestone for archaeological research. Its technical development over the last decades has expanded, to extremes difficult to imagine not long ago, the possibilities of addressing historical chronological problems from the analysis of archaeological contexts. However, during this time it has also been shown that, for these purposes, the usefulness of the 14C dates not only depends on the reliability of the contexts of provenance of the dated samples. Acceptance of their validity as an archaeological data will depends also on its coherence with the rest of the available information. In this paper, we present a critical assessment of the radiocarbon dating obtained up to this moment in the Tabayá site (Aspe, Alicante), relating to its Argaric occupation, and the arguments that have led us to consider as invalid two of them, taken from the tomb 1 . Both show serious inconsistencies in relation to the recorded stratigraphy and to the dates obtained for the tomb 3. Finally, a relative chronology is proposed for the tomb 1 of the Tabayá from the radiocarbon dates of infirmed levels to this one, and tomb 3 , as well as stratigraphic data that relate both tombs.

Key words: Radiocarbon, Bronze Age, Argar culture, burials, stratigraphy. 


\section{INTRODUCCIÓN}

Desde que en el año 1946 el químico W. L. Libby (1952) propusiera la medición del ${ }^{14} \mathrm{C}$ para obtener dataciones de muestras de materias orgánicas, los estudios arqueológicos dieron un salto cualitativo de especial trascendencia. El hecho de que su implementación coincidiera con el desarrollo del cientifismo en arqueología (Watson, Leblanc y Redman 1971; Renfrew 1973) supuso, además de una veloz difusión del manejo de esta técnica en casi todos los rincones del planeta, una auténtica revolución en el plano metodológico e interpretativo en la que, de algún modo, aún estamos embarcados (Bayliss 2009).

Hoy es evidente que el empleo del ${ }^{14} \mathrm{C}$, apoyado en los estudios estratigráficos, ha permitido acotar la dimensión temporal en arqueología con una precisión que a mediados del siglo pasado apenas se podía siquiera sospechar, tanto en lo que se refiere a la determinación cronológica de la ocupación de los yacimientos arqueológicos, como en la concreción de las divisiones de los tiempos prehistóricos al uso.

Sin embargo, a lo largo de las últimas décadas hemos asistido al desarrollo de diversos problemas interpretativos y a largos y estériles debates provocados por el exceso de confianza depositado en la fiabilidad de esta técnica, de cuyos límites, en buena medida, no se fue consciente, lo que impidió mantener una posición suficientemente crítica con respecto al alcance y valor del tipo de determinaciones que proporcionaba.

En el caso concreto de la Edad del Bronce en el Sureste y Levante de la península ibérica, desde los años 1960 hasta bien entrada la década de 1990 el uso de fechas aisladas a partir del análisis de muestras, en su mayor parte de carbón, fueron las bases sobre las que se fue definiendo el desarrollo temporal de la cultura de El Argar y de otras áreas culturales, como el llamado Bronce Valenciano (Gilman 2003; Jover y López 2009). Sin embargo, hacia mediados de los años 1980 ya se hacía evidente la necesidad de revisar las dataciones obtenidas, a lo que obligaba, por un lado, su calibración y transformación en fechas calendáricas, y por otro, el ineludible descarte de las muestras de vida larga (Schiffer 1986) y con desviaciones estándar demasiado elevadas. Pronto se hicieron, además, evidentes las ventajas de disponer de amplias series de dataciones con el objeto de concretar con mayor precisión, tanto la secuencia cronológica de los asentamientos excavados como la cronología de determinados contextos o de evidencias singulares de especial significación. A finales de los años 1990 el número de dataciones había crecido tanto que se hicieron necesarios importantes trabajos de recopilación y análisis de amplios conjuntos de dataciones para ámbitos geográficos extensos (Castro, Lull y Micó 1996). Así mismo, pudieron ensayarse diversas propuestas de periodización a partir de las primeras baterías de dataciones procedentes de yacimientos ampliamente excavados (González Marcén 1994; Mederos 1995; Jover 1999), las cuales, a la postre, se revelaron esencialmente inútiles debido a los sesgos introducidos por la amplia variabilidad y calidad heterogénea de las muestras datadas (Jover y López 2011: 216).

Con el nuevo milenio, el número de fechas de ${ }^{14} \mathrm{C}$ se ha multiplicado de forma exponencial gracias al desarrollo y generalización de la técnica de espectrometría de masas con acelerador-AMS-, que permite la obtención de dataciones a partir de muestras orgánicas de tamaño ínfimo. Esto ha facilitado la selección preferente de muestras de vida corta y maximizar la fiabilidad estratigráfica de sus contextos de procedencia. Por su parte, los laboratorios han venido mejorando la calidad de las determinaciones, reduciendo su desviación estándar y empleando curvas de calibración cada vez más precisas, al tiempo que se perfeccionaban y aplicaban nuevos procedimientos técnicos en el tratamiento de las muestras, como el ultrafiltrado en los procesos de gelatinización de las muestras óseas o los análisis isotópicos destinados a determinar la calidad de las mismas (Reimer et al. 2013; Higham, Jacobi y Bronk Ramsey 2006; Brock et al. 2010). El último gran avance, al que estamos asistiendo en la actualidad en nuestro país, ha sido la aplicación a las series radiocarbónicas de los modelos de estimación estadística basados en los principios de la estadística bayesiana (Buck, Cavanagh y Litton 1996; Buck, Christen y James 1999; Buck 2003; Millard 2005; Bronk Ramsey 2009), lo que ha venido a repercutir en una mejora ostensible en las posibilidades de abordar y resolver los problemas cronológicos planteados por la investigación arqueológica, como ponen de relieve algunos de los últimos trabajos publicados (Lull et al. 2010; 2013; Aranda y Lozano 2014; 2017; Bronk Ramsey et al. 2016, entre otros).

No podemos más que considerar, por tanto, que la introducción del radiocarbono ha supuesto un impulso fundamental que ha permitido acercar los tiempos arqueológicos a las necesidades que plantean los análisis históricos. Sin embargo, cuatro largas décadas deben servirnos hoy para justificar una actitud más crítica y prudente frente a los datos que el ${ }^{14} \mathrm{C}$ proporciona, ser plenamente conscientes de sus límites y evaluar las eventuales contradicciones que tales datos puedan plantear con respecto del conjunto del registro 
arqueológico. En este trabajo pretendemos exponer, a partir de un caso concreto - la datación radiocarbónica de la tumba 1 del asentamiento del Tabayá- los problemas de índole interpretativa a los que puede conducir el radiocarbono y cómo únicamente desde la valoración de la estratigrafía y del registro arqueológico es posible detectarlos y resolverlos.

\section{EL TABAYÁ. UN ASENTAMIENTO EN LA FRONTERA NORORIENTAL DEL TERRITORIO ARGÁRICO}

En el marco de los estudios sobre la Edad del Bronce en el Sureste de la península ibérica, y del grupo argárico en particular, el yacimiento del Tabayá -o Tabaià- (Aspe, Alicante) ocupa un lugar de referencia. Esta circunstancia se explica, básicamente, por la concurrencia de tres aspectos de gran relevancia: en primer lugar, por la incontestable índole argárica de una parte de su secuencia de ocupación, prontamente revelada por las campañas de excavación realizadas y que depararon, entre otros hallazgos, el que continúa siendo hoy el único enterramiento con alabarda (Hernández 1990) localizado en territorio alicantino desde los trabajos de Josep Colominas en Laderas del Castillo (Callosa de Segura, Alicante), hace ya casi un siglo (Colominas 1936); en segundo, por su situación geográfica en lo alto de la sierra homónima, justo sobre el borde de lo que durante mucho tiempo constituyó la frontera política del territorio nororiental argárico (Jover y López 1997), y que lo convierte en una pieza esencial para la comprensión de los procesos de cambio y de contacto intersocial entre la sociedad argárica y los grupos arqueológicos periféricos; y por último, por su prolongada secuencia de ocupación que, a la luz de los datos que hoy conocemos, abarca desde la segunda mitad del III hasta bien entrado el I milenio a.n.e. Los diferentes estudios publicados hasta la fecha permiten avanzar un relato arqueológico suficientemente consistente acerca de las diversas fases de ocupación reconocibles en el asentamiento.

El yacimiento del Tabayá se localiza sobre un espolón rocoso del extremo más occidental de la sierra del mismo nombre, justo sobre la margen izquierda del río Vinalopó, encajado en este punto en una angosta garganta que ha servido históricamente para fijar la divisoria entre sus cuencas media y baja, al tiempo que ha constituido, por esa misma razón, un punto de importancia estratégica excepcional desde la Prehistoria hasta casi los tiempos modernos (fig. 1).
Conocido como yacimiento arqueológico desde comienzos del siglo XX (Jiménez de Cisneros 1910: 5), los primeros estudios científicos no fueron realizados hasta finales de los años 1970 e inicios de los 1980 (Navarro 1982; Hernández 1983), basados en el análisis de los materiales recogidos en sus laderas por excursionistas y aficionados locales. Estos trabajos reafirmaban la importancia del sitio durante la Edad del Bronce en las comarcas meridionales valencianas, en un momento en el que el debate acerca del origen y de la demarcación territorial entre El Argar y el denominado Bronce Valenciano centraba la mayor parte de la atención entre los investigadores (Lull 1983; Bernabeu 1984; Hernández 1986).

Este interés motivó la realización de excavaciones en el yacimiento por parte de la Universidad de Alicante, llevadas a cabo bajo la dirección de uno de nosotros (Hernández 2009). Los trabajos se desarrollaron en campañas anuales de tres o cuatro semanas de duración, entre los años 1987 y 1991, sumándose a la dirección de las campañas finales José Luis Simón García y José Antonio López Mira.

A lo largo de las tres últimas décadas buena parte de los materiales exhumados en estas campañas han sido objeto de diferentes estudios. Previamente, a finales de los años 1980, se llevó a cabo una revisión e inventario de los objetos depositados en diferentes colecciones privadas y en el Museo Arqueológico de Novelda, en el marco de un estudio general de los yacimientos de la Edad del Bronce del valle medio del Vinalopó, que desafortunadamente quedó inédito. En él ya se daba cuenta de una de las tumbas expoliadas, correspondiente al enterramiento en urna de una mujer, con un ajuar integrado por un par de pequeños aretes de metal, un punzón de hueso y una tulipa de excelente factura (Jover y López 1997: 56) (fig. 2). En lo que respecta al conjunto cerámico, los materiales del Bronce Final hallados en la zona más alta del emplazamiento fueron los primeros en ser publicados (Hernández y López 1992); los recipientes del Corte 8 fueron analizados por F. A. Molina Mas (1999), si bien de estos solo se publicaron los correspondientes a los niveles del Bronce Tardío y Bronce Final, al igual que ocurrió con los del Corte 11, estudiados por D. Belmonte Mas (2004). Por su parte, los objetos metálicos y artefactos relacionados con la producción metalúrgica fueron analizados por J. L. Simón García (1998) en el marco de su tesis doctoral. El estudio de los productos líticos, óseos y los relacionados con la producción textil fueron también abordados en los proyectos de tesis doctorales de F. J. Jover Maestre (1997), J. A. López Padilla (2011) y J. A. López Mira, 

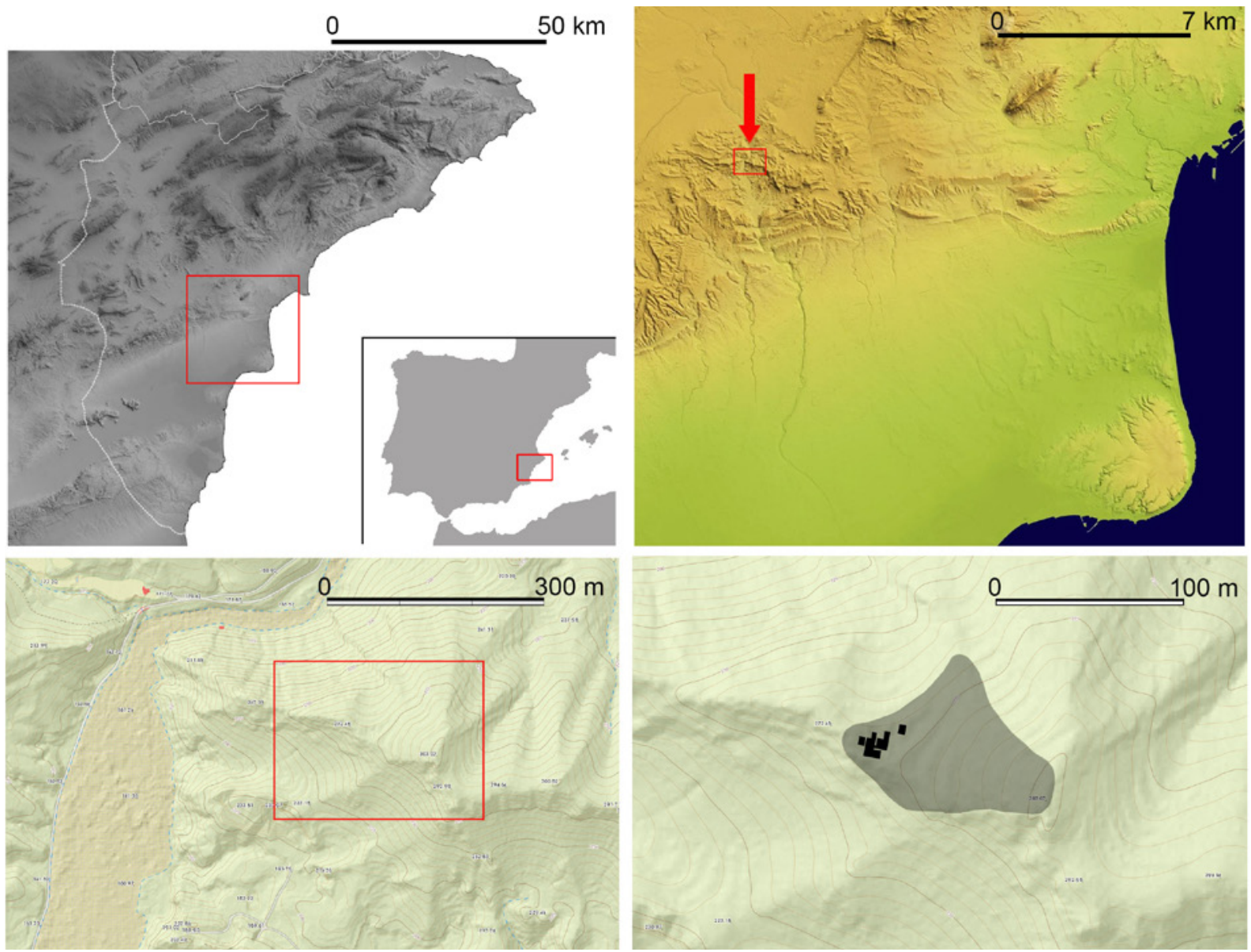

Figura 1. Localización del yacimiento arqueológico del Tabayá e indicación de los cortes abiertos en la terraza inferior y de la extensión superficial aproximada.

respectivamente. M. ${ }^{a}$ P. de Miguel Ibáñez (2003) realizó el estudio antropológico y paleopatológico de los restos humanos localizados en las sepulturas, de las que ya hace algunos años se dio noticia detallada (Hernández y López 2010) y C. Rizo Antón (2009) publicó el estudio arqueozoológico del Corte 11. Finalmente, V. Barciela González (2016) ha abordado el análisis de los elementos de adorno, también en el marco de su tesis doctoral.

Pero, posiblemente, el hallazgo más repetidamente consignado en la bibliografía es el de la tumba individual en cista de mampostería localizada en el corte 11 en la campaña de 1988 -tumba 1-que, como ya hemos mencionado, permitió en su momento corroborar la vinculación del asentamiento con el ámbito argárico (Hernández 1990; Badal 1990; Simón 1998). Entre 1987 y 1991 se documentó una decena de enterramientos más. Algunos de ellos, desafortunadamente saqueados para extraerles los objetos que tuvieran adheridos a brazos, piernas y cráneo, pertenecen a momentos avanzados del II milenio cal BC -Bronce Tardío-Final- pero, por su situación estratigráfica, ritual y ajuar, el resto pueden considerarse claramente argáricos (Hernández y López 2010) (fig. 3).

Los distintos momentos de la ocupación prehistórica del Tabayá han podido establecerse a partir del análisis del registro cerámico $\mathrm{y}$, en menor medida, de otros elementos de la cultura material, conjuntamente con los enterramientos documentados. La información estratigráfica más detallada proviene de los cortes 8 , 10 y 11 , todos ellos contiguos y ubicados en la terraza de la ladera septentrional (López Padilla 2011: 162; Barciela 2016: 576).

A partir de estos datos se han identificado cinco grandes fases arqueológicas sucesivas, a las que se pueden añadir otras, deducidas de evidencias aisladas en 
otros puntos de sus laderas. La primera de ellas -fase I- correspondería a momentos finales del Calcolítico e iniciales de la Edad del Bronce, con los que cabría relacionar posiblemente los fragmentos de un cuenco con decoración campaniforme de tipo Ciempozuelos y de fragmentos de campaniformes incisos localizados por aficionados locales en diversos puntos de las laderas del yacimiento (Hernández 1982: 15 y 16). En los cortes 8 y 11 se registraron numerosos fragmentos cerámicos, por lo general de pequeño tamaño, pertenecientes a recipientes de perfiles curvos, en su gran mayoría de escasa capacidad. Entre estas cerámicas destacan unos pocos fragmentos decorados con líneas incisas y puntillado en las zonas del borde, cuello y cuerpo, formando motivos de líneas horizontales paralelas al borde de las que cuelgan otras en zigzags, y triángulos incisos rellenos de puntillado, que ya en su momento se relacionaron con una tradición epicampaniforme cuyo origen último podría encontrarse en las vasijas decoradas del cercano yacimiento de Promontori d'Aigua Dolça i Salada, en Elche (Hernández 1997: 102).

La siguiente fase -fase II- es incuestionablemente argárica, como muestran tanto los hallazgos cerámicos -entre los que no son extrañas las vasijas con carenas acusadas, de pastas y tratamientos de buena calidad y algunos pies de copas- como el utillaje metálico y el tipo y ajuares de las tumbas. A esta fase pertenecen todas las dataciones absolutas obtenidas hasta el momento, provenientes de las tumbas 1 y 3 , y que, hasta ahora, fijaban un amplio intervalo a lo largo de la primera mitad del II milenio cal BC para este nivel de ocupación.

La fase III se asocia al denominado Bronce Tardío (Molina 1978) -aproximadamente entre ca. 1550/1500-1300/1250 cal BC- por la presencia de cerámicas de pastas de buena calidad, en las que predominan las fuentes y cazuelas de carena alta, algunas bases con ónfalo o con pie indicado y escasos fragmentos decorados con la técnica del boquique (Molina 1999; Belmonte 2004). Las pesas de telar con cuatro perforaciones de la fase anterior son sustituidas ahora por las cilíndricas con una perforación (López Mira 2009). Esta Fase III del Tabayá se podría relacionar por sus materiales con el desarrollo del Cabezo Redondo de Villena (Hernández 2012), que se abandona a finales del Bronce Tardío.

La siguiente fase -fase IV- correspondería al Bronce Final II (Jover, Lorrio y Díaz 2016), cuyas evidencias se han podido constatar en el último momento de ocupación de la plataforma inferior, en muchos puntos alterada por la erosión, las remociones agrícolas y las actividades clandestinas que no permiten

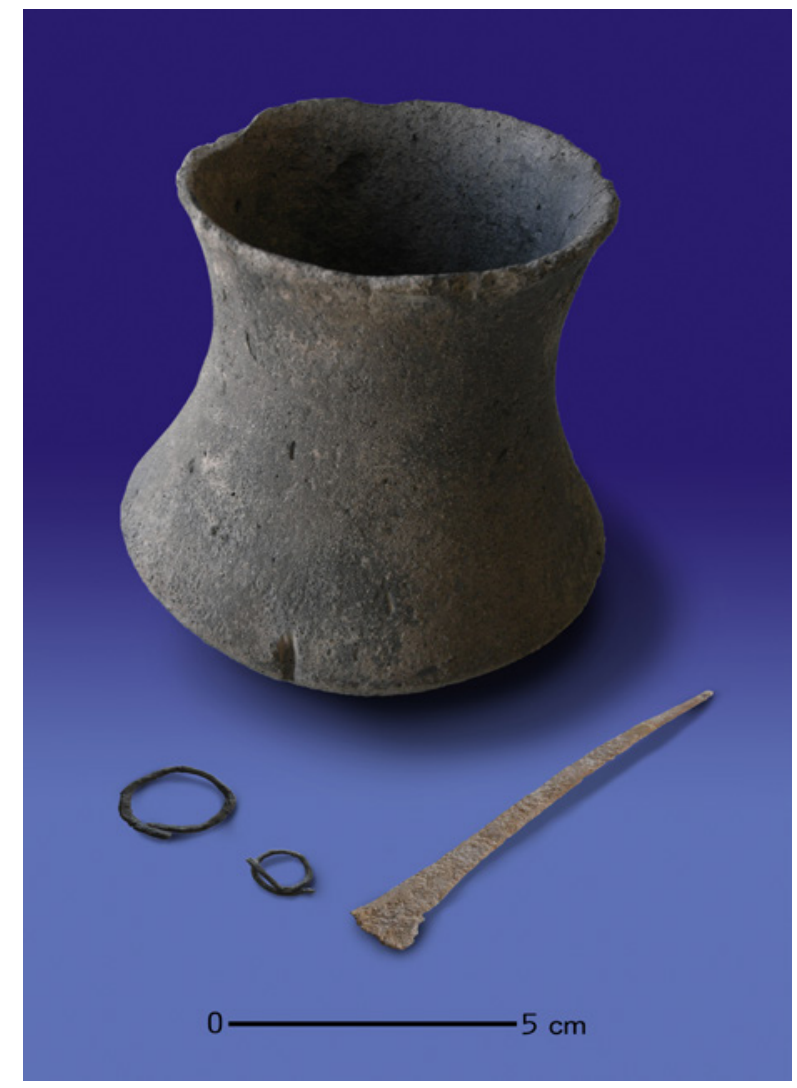

Figura 2. Ajuar funerario procedente de un enterramiento femenino en urna localizado en el Tabayá. Materiales depositados en el Museo Arqueológico Municipal de Novelda (Alicante).

precisar las construcciones de este momento ni el tipo de contacto con el Bronce Tardío. Por otro lado, en la parte alta de esta ladera-cortes 1 a 6 -, el único nivel detectado corresponde igualmente al Bronce Final II, pero en este caso, con materiales similares a los recuperados en la plataforma inferior (Hernández y López 1992). Esta ocupación se desarrollaría en el tránsito del II al I milenio cal BC, dada la presencia de cerámicas acanaladas de tipo campo de urnas (Jover, Lorrio y Díaz 2016).

Por último, aunque no haya sido atestiguado en las diferentes campañas de excavación efectuadas, del Tabayá se conservan en el Museo Arqueológico Municipal de Novelda diversos materiales cerámicos a torno y metálicos que plantearían su ocupación durante el Hierro antiguo (Moratalla 2005). Estos materiales, al parecer, procederían de puntos imprecisos de la ladera meridional, constituyendo el final de la ocupación del asentamiento -fase $\mathrm{V}$-. 


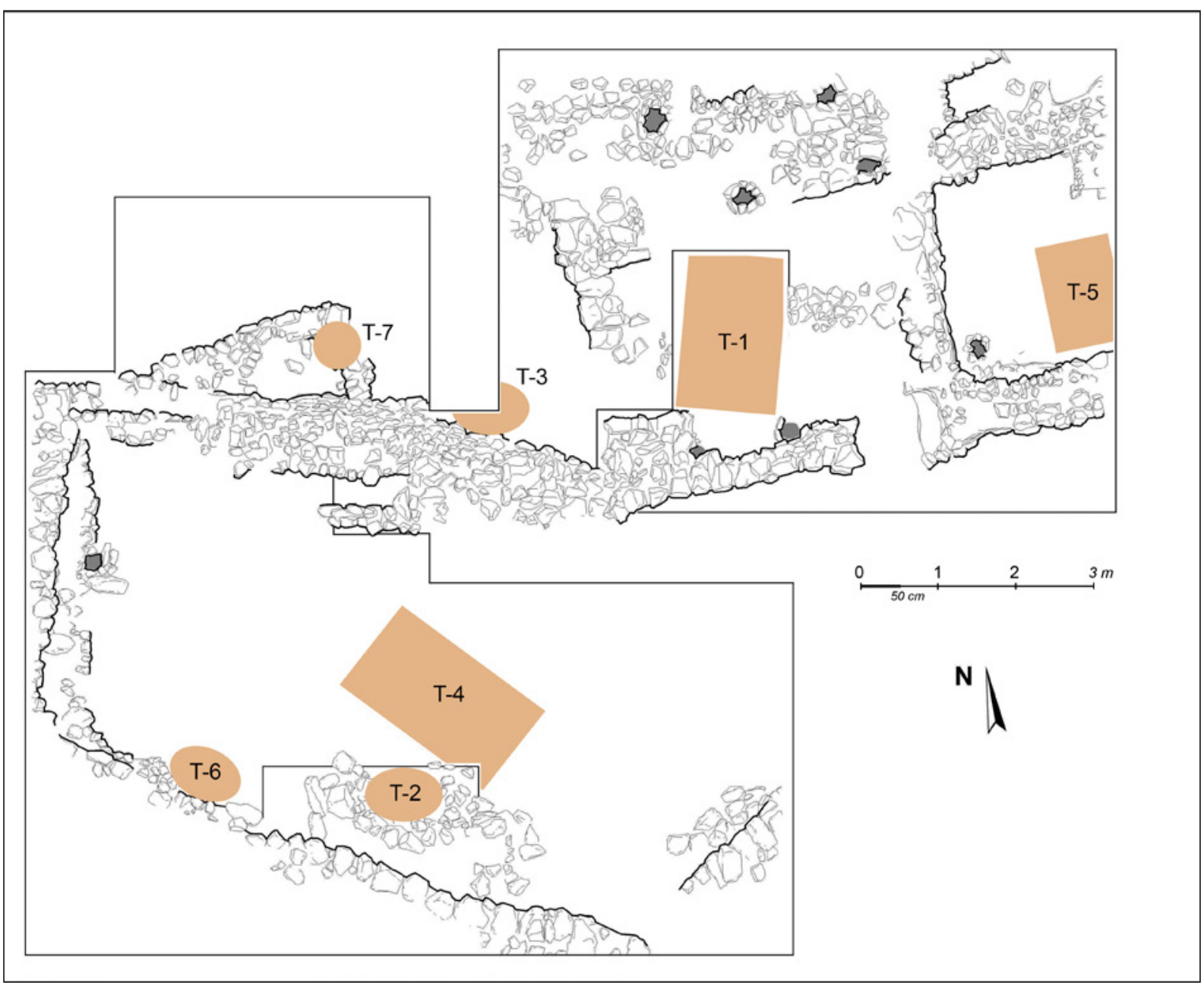

Figura 3. Planta general de estructuras de las fases I y II de la Terraza Inferior del Tabayá, con indicación de las sepulturas de cronología argárica halladas.

\section{EL YACIMIENTO DEL TABAYÁ EN EL MARCO DE LA SECUENCIA \\ RADIOCARBÓNICA DE EL ARGAR: EL PROBLEMA DE LAS DATACIONES DE LA TUMBA 1}

Una de las informaciones dada a conocer hace ya casi una década fue la relativa a las dataciones radiocarbónicas, obtenidas a partir de varias muestras de hueso de las tumbas 1 y 3 , enterramientos ambos documentados en la terraza inferior del yacimiento (Hernández 2009; Hernández y López 2010). No obstante, hasta la actualidad, y por diversas razones que expondremos convenientemente en este trabajo, las fechas proporcionadas por dichas muestras, entregadas por los laboratorios de Beta Analytic (Miami, EEUU) y el Leibniz-Labor für Altersbestimmung und Isotopenforschung (Kiel, Alemania) en 2008 y 2009, respectivamente, no habían podido contribuir a afianzar el esqueleto cronológico que acompaña a la potente estratigrafía del yacimiento, ni a fijar en un intervalo temporal más o menos preciso el enterramiento de la tumba 1, cuyas características y ajuar se revelaron desde el comienzo de las investigaciones como una pieza clave en el análisis del proceso de implantación y ocupación argárica del Tabayá.

No hace mucho se estimaba que el territorio alicantino apenas había proporcionado un $8 \%$ de las dataciones referidas a contextos argáricos de la península ibérica, mientras que casi el $80 \%$ del total procedía de yacimientos almerienses y granadinos (Aranda, Montón y Sánchez 2015). Lo cierto es que hasta 2005 la 

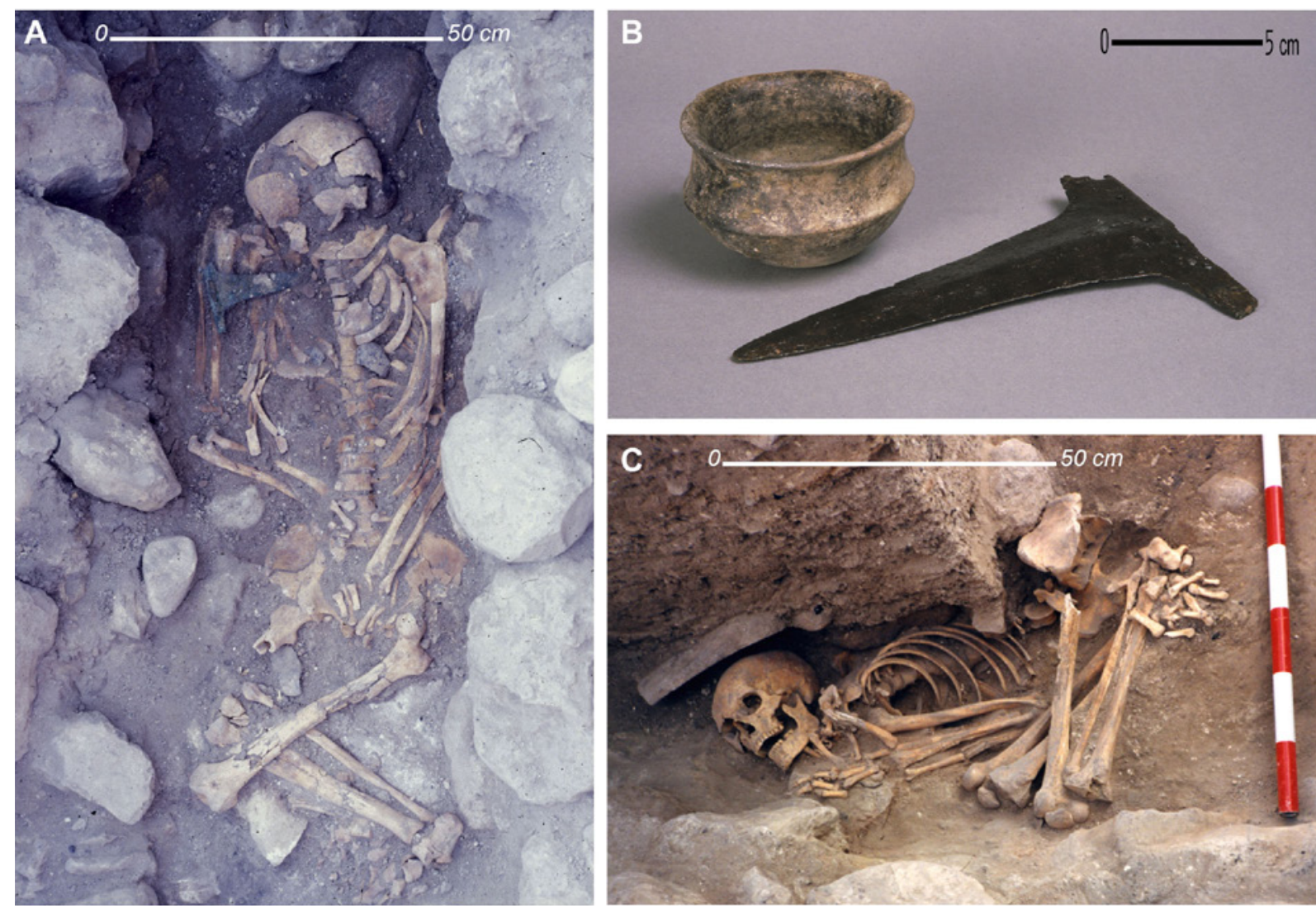

Figura 4. Sepulturas argáricas del Tabayá. A: Tumba 1. B: Ajuar cerámico y metálico de la tumba 1. C: Tumba 3.

única datación radiocarbónica disponible para un asentamiento argárico de Alicante provenía de Pic de les Moreres, en Crevillent (González Prats 1986: 210), la cual, además, sería desestimada como datación válida solo una década más tarde de su publicación, a causa de los controvertidos resultados ofrecidos por el laboratorio japonés que la había suministrado y por otras irregularidades de la propia muestra enviada (Castro, Lull y Micó 1996: 31). Puede afirmarse, por tanto, que la secuencia radiocarbónica en el área argárica del sur de la provincia de Alicante se inaugura a comienzos de este siglo, durante los trabajos de excavación que acompañaron el proyecto de musealización de la Illeta dels Banyets por parte del Museo Arqueológico de Alicante-MARQ (Soler 2005).

En el marco de esta investigación, que conllevó el reestudio, análisis y evaluación de los restos materiales exhumados en este yacimiento durante las campañas dirigidas por E. Llobregat entre 1974 y 1986, se impulsó un programa de datación radiocarbónica de los enterramientos argáricos que, iniciado con las sepulturas de la Illeta dels Banyets (López, Belmonte y de Miguel 2005), continuaría más tarde con la datación de las tumbas 1 y 3 del Tabayá y la tumba 1 de Cabezo Pardo (López Padilla 2009). En la actualidad, el número de dataciones disponible para tumbas argáricas en Alicante se eleva ya a una veintena, de las que tan solo permanecen todavía inéditas las de las tumbas 3, 5, 6 y 7 de Laderas del Castillo (Callosa de Segura).

Por razones obvias, de todo el registro funerario del Tabayá, la sepultura de la que resultaba prioritario disponer de datación radiocarbónica era la tumba 1 (fig. 4.A). Este enterramiento, ya ampliamente referenciado en la bibliografía (Hernández 1990; 1997; 2009; Jover y López 1997; Hernández y López 2010) estaba conformado por una cista de mampostería irregular, de forma aproximadamente rectangular, con esquinas redondeadas, que fue cerrada también con mampuesto mezclado, presumiblemente, con tablas, listones o rollizos de madera. El hueco interior de la caja tenía unas dimensiones de aproximadamente 1,35 $\mathrm{m}$ de largo por unos 0,45 $\mathrm{m}$ de ancho. En este espacio se realizó la inhumación de un hombre adulto-joven, dispuesto en posición decúbito supino con las piernas flexionadas hacia 
la derecha, y los brazos cruzados a diferente altura, con la mano izquierda sobre la parte inferior del abdomen y la izquierda ligeramente por encima de aquella. La disposición de los tarsos, metatarsos y falanges, no obstante, señalaba inequívocamente que los pies estaban juntos, prácticamente en contacto uno con otro por su cara interna, lo que hace pensar que quizá la posición original de las piernas fuera otra, con las plantas de los pies apoyadas en el suelo y las rodillas flexionadas a cierta altura por encima de la cadera, circunstancia a la que también apuntaría el hecho de que durante la excavación de la cista, las dos rótulas y parte del extremo distal del fémur derecho se recuperaran a una cota menor que el resto del esqueleto. Esta posición, aunque no habitual en las tumbas argáricas, no es tampoco completamente excepcional (Hernández y López 2010: 225). Uno de los casos mejor documentado es el enterramiento 12 del Convento de las Madres Mercedarias, en el casco urbano de Lorca (Martínez, Ponce y Ayala 1996: 44-47; Martínez y Ponce 2002: 124-126). Aunque se trata de la sepultura de una mujer adulta, sus similitudes con la tumba 1 del Tabayá son muy notables: en ambos casos el contenedor es una cista de mampostería de planta pseudo-rectangular, con el esqueleto en posición decúbito supino, los pies juntos, los brazos cruzados y las manos sobre el bajo vientre. Sin embargo, en este caso, tras la ruptura de ligamentos y tendones a causa de la putrefacción del cadáver, las piernas cayeron hacia lados opuestos, disponiendo fémures y tibias en una postura extremadamente forzada, con las plantas de los pies enfrentadas, cerca del coxis. Otro ejemplo perfectamente parangonable con el enterramiento de la tumba 1 del Tabayá es el alabardero hallado en la sepultura 60 de La Almoloya, también en posición decúbito supino con las piernas flexionadas y que, como en nuestro caso, mostraba la hoja de la alabarda dispuesta junto a su hombro derecho (Lull et al. 2017a: 154, fig. 7). El estudio antropológico realizado por M. P. de Miguel (2003: 265) reveló, además de algunas particularidades óseas y bucales y la confirmación del sexo masculino del individuo -corresponde al individuo $\mathrm{n}^{\circ} 7$ de su inventario-indicios de sinóstosis en las suturas craneales y la eclosión del tercer molar, todo lo cual apuntaba a un hombre de edad adulta, pero joven, con una talla aproximada de $1,67 \mathrm{~m}$.

Por lo que respecta al ajuar (fig. 4.B; 5.B), sobre el hombro derecho descansaba la hoja de una alabarda de $17 \mathrm{~cm}$ de longitud, con una marcada nervadura central y una estrecha placa de enmangue de $12,3 \mathrm{~cm}$ atravesada por 6 remaches, uno de ellos de sección circular y el resto de sección cuadrada (Hernández 1990: 88, fig. 2; Simón 1998: 65, fig. 37.1). Detrás del cráneo, a la altura del occipital, se localizó un pequeño vasito carenado de la forma 5 de Siret, de buena factura, de apenas $5,8 \mathrm{~cm}$ de alto y $7,9 \mathrm{~cm}$ de diámetro de boca y de carena (Hernández 1990: 88, fig.3). Tanto el cráneo como el recipiente se hallaban ligeramente desplazados de su posición original, alterada por el desplome de los mampuestos de la cubierta de la cista. El pequeño vaso estaba volcado y el cráneo aparecía con el rostro parcialmente hundido sobre el hombro derecho, al tiempo que la mandíbula se había desprendido y desplazado hacia el hombro izquierdo. De todo ello cabe deducir que originalmente el vaso debió estar dispuesto al lado de la cabeza del difunto, en su lado izquierdo. Por último, cuidadosamente dispuesta junto al antebrazo derecho, se hallaron el radio y la ulna de un ovicaprino joven, pertenecientes a la pata delantera derecha de un cordero o cabrito.

El hallazgo de esta sepultura en 1988 venía a otorgar verosimilitud a las noticias que, años antes, habían circulado en torno a la existencia de tumbas y materiales de inequívoca tipología argárica en el yacimiento (Navarro 1982: 63). En concreto, del Tabayá se conocía ya la existencia de una alabarda, perteneciente a la colección privada de A. Alberola, de Novelda, Alicante. La pieza posee una nervadura marcada y presenta la zona del enmangue fragmentada, aunque dejando visibles las huellas de dos orificios para remaches -de los que sin embargo no conserva ninguno- y para la que se señalaron similitudes con ejemplares como la alabarda de la tumba 200 de El Oficio (Hernández 1983: 33). En la actualidad conserva una longitud de $17,7 \mathrm{~cm}$, una anchura máxima de $8,8 \mathrm{~cm}$, y un peso de $117,5 \mathrm{~g}$ El análisis metalográfico reveló un altísimo porcentaje de cobre y valores apenas testimoniales de estaño, arsénico y níquel (Simón 1998: 259) (fig. 5.A).

A pesar del interés que ofrecía el hallazgo de esta alabarda en el yacimiento, la ausencia de contexto o de referencias estratigráficas constituía un serio problema. Sin embargo, la excavación de la tumba 1 brindaba ahora, por primera vez, la posibilidad de obtener un horizonte cronológico para este tipo de objetos, tan característicamente argáricos y especialmente abundantes en el territorio meridional de Alicante. Se estimó conveniente seleccionar dos muestras: una del esqueleto humano y otra de la ofrenda cárnica, de manera que la calibración conjunta de ambas permitiera acotar al máximo el intervalo cronológico señalado por el ${ }^{14} \mathrm{C}$. En consecuencia, en enero de 2008 se remitieron al laboratorio Beta Analytic de Miami (EEUU) las muestras TA-88-C11-1 -consistente en 


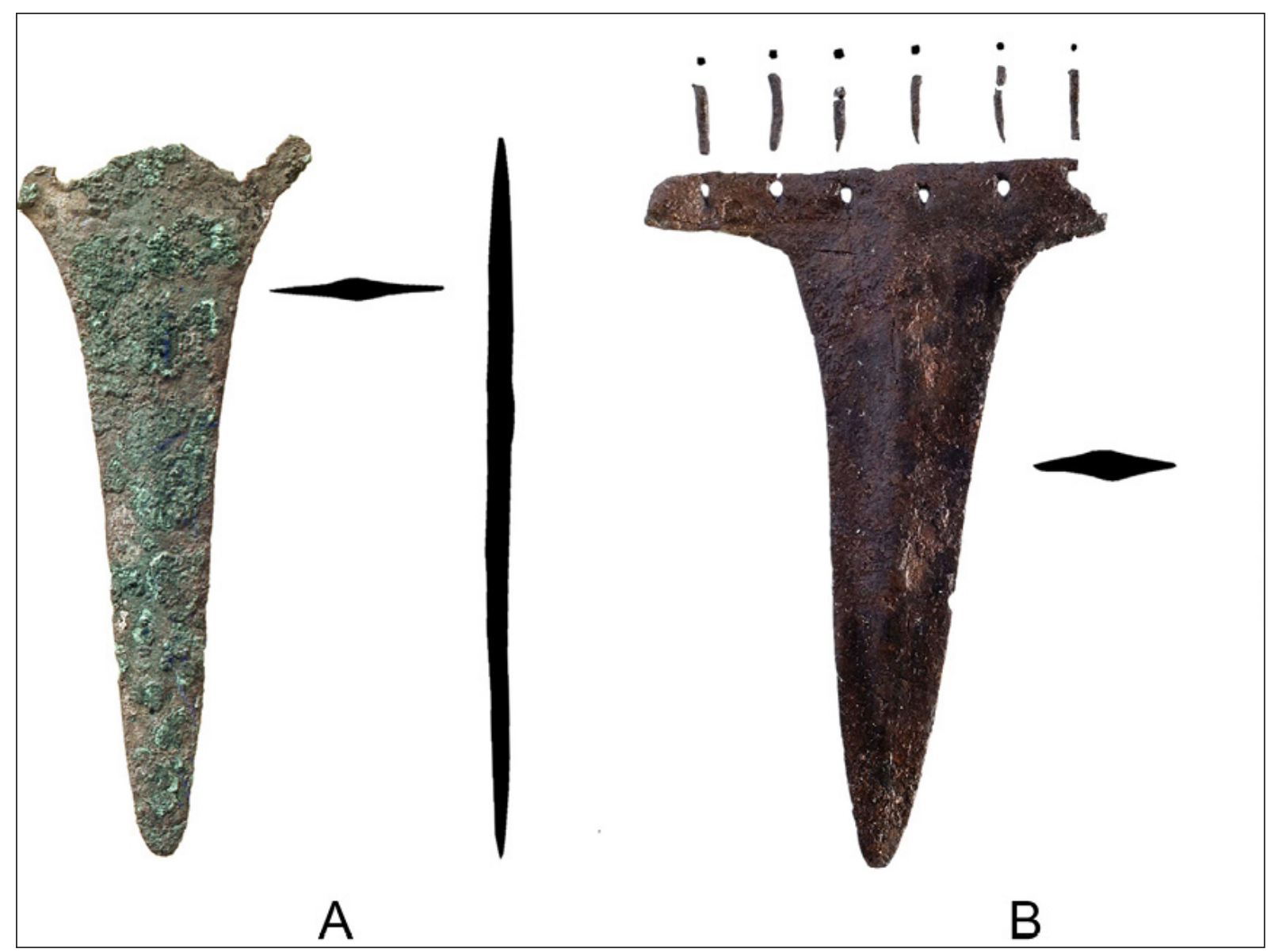

Figura 5. Alabardas del Tabayá. A: Alabarda perteneciente a la Colección Alberola (Novelda, Alicante); B: Alabarda procedente del ajuar de la tumba 1. (Fotomontaje digital realizado a partir de fotografías de M.S. Hernández y dibujos de J. L. Simón).

el radio-ulna derecho de un ovicaprino joven, con un peso de 23,9 gr- y TA-88-C11-2 -un fragmento del peroné derecho del esqueleto humano, con un peso de 49,4 gr-. Una vez finalizado el pretratamiento de las muestras, se evidenció que la segunda de ellas no proporcionaba colágeno suficiente para proceder a la datación. Ello motivó que se extrajera una segunda muestra suplementaria del mismo hueso -el peroné derecho-, esta vez con un peso de 63,2 gr, que fue enviada también a Miami. Finalmente, Beta Analytic procedió a remitir un informe con las dataciones obtenidas a finales de febrero de 2008.

Al margen de que las dos fechas resultaban sorprendentemente modernas para el tipo de enterramiento y ajuar funerario de la tumba, se pudo comprobar enseguida que existían anomalías difícilmente justificables desde un punto de vista meramente estratigráfico, ya que las fechas del esqueleto y del hueso de cabrito que le acompañaba guardaban entre sí una distancia temporal muy considerable (tab. 1; fig. 6). Además, la hipótesis de que la ofrenda cárnica hubiera estado depositada en el interior de la tumba prácticamente un siglo antes de que se realizara el enterramiento resultaba sumamente improbable y carente de sentido. Las fechas de ambas muestras debían mostrar una compatibilidad coherente con el hecho de proceder de un mismo y único evento: el enterramiento de la tumba 1. Las sospechas de que el colágeno de las muestras estaba contaminado y que las dataciones no podían considerarse válidas surgieron de inmediato.

Alertado el laboratorio Beta Analytic de esta circunstancia, en aquel momento sus explicaciones se limitaron a señalar que, dado que las fechas provenían de dos muestras diferentes -el esqueleto humano y el hueso de ovicaprino- y que ambas dataciones ofrecían un pequeño intervalo de solapamiento en el rango correspondiente a $2 \sigma$, estadísticamente podían considerarse equivalentes. Sin embargo, por mucho que el 
contexto estratigráfico de las muestras datadas avalara su calibración conjunta, la combinación de las dataciones resultaba completamente desaconsejable, como se pone de manifiesto al tratar de crear un valor combinado en el programa OxCal -v.3.10-:

Combine (Tumba 1: Beta-240409 / Beta-240410): 1859 $-1631 \mathrm{cal} \mathrm{BC}(95,4 \%)$

Warning! $\chi$-Test fails at 5\% - (Tumba 1: Beta-240409/ Beta-240410)

$\chi^{2}$-Test: $\mathrm{df}=1 \mathrm{~T}=5.471(5 \% 3.8)$

Warning! Poor agreement $-\mathrm{n}=2 \mathrm{Acomb}=32.6 \%(\mathrm{An}=$ $50.0 \%)$

La operación no supera el test de $\chi^{2}$, de acuerdo con los parámetros del programa, indicando claramente que la fecha resultante de la combinación de ambas dataciones presenta una probabilidad inferior al 5\% de ser una fecha cierta. Para que eso ocurriera, el valor de " $\mathrm{T}$ " -5.47- debería ser inferior a 3.80, cuando sucede claramente lo contrario. De todos modos, el parámetro clave aquí es el valor de Acomb, que presenta un porcentaje de compatibilidad para la combinación de ambas fechas de $32.6 \%$, muy lejos del valor de An $-50 \%-$ que debería superar $-\mathrm{O}$, al menos, igualar- para considerarla una combinación de fechas verosímil (Bronk Ramsey 1995; 2001). En consecuencia, la explicación más plausible apuntaba a la contaminación del colágeno extraído de las muestras.

Como es bien sabido, la contaminación en la muestra puede variar el resultado de la fecha obtenida en dos direcciones: atribuyéndole una antigüedad superior a la real cuando los ácidos húmicos incluyen carbonatos de la roca caliza del entorno -con una edad geológica muy superior-, o haciéndola parecer más reciente, cuando los componentes contaminantes proceden del sustrato edáfico en el que se produce la degradación microbiana de plantas y animales. En el caso específico de las muestras óseas, los laboratorios aplican un pretratamiento químico que comúnmente conlleva el uso de ácido hidroclorídrico y un lavado alcalino posterior para eliminar ácidos orgánicos secundarios (Longin 1971). No obstante, se ha señalado en varias ocasiones que este procedimiento no garantiza absolutamente la eliminación de carbono exógeno, especialmente en el caso de huesos con un bajo contenido en colágeno. Para solventar este problema, en la actualidad algunos laboratorios, como el Oxford $R a$ diocarbon Accelerator Unit -ORAU- o el Laboratorio de Isótopos Estables del Max-Planck-Institut für evolutionäre Anthropologie de Leipzig emplean de forma sistemática el procedimiento del ultrafiltrado, que consiste en separar los componentes moleculares más grandes y pesados del colágeno gelatinizado de las fracciones moleculares más pequeñas, entre las que se incluirían fragmentos degradados del colágeno además de sales y aminoácidos procedentes del suelo (Bronk Ramsey et al. 2004; Higham, Jacobi y Bronk Ramsey 2006). A pesar de que ha demostrado ser un sistema que mejora las condiciones de la muestra para su datación radiocarbónica, el ultrafiltrado exige una inversión de trabajo mayor en su procesado, motivo por el que incluso hoy apenas un puñado de laboratorios en todo el mundo aplican este sistema de forma regular, y solo unos pocos más ofrecen este servicio bajo demanda del cliente y a costa de un incremento de la tarifa. Este criterio no se apoya solo en principios mercantilistas, sino también en los resultados de diversos test realizados en los últimos años, en los que no se acredita la existencia de sustanciales diferencias en la calidad de las muestras de colágeno obtenidas con o sin ultrafiltrado (Sealy et al. 2014). Sin embargo, no es menos cierto que dichos test se han referido siempre a muestras de hueso en buen estado.

Existe una serie de parámetros a partir de los cuales es posible evaluar la calidad de una muestra ósea para su datación por radiocarbono. Además de los valores referidos a la concentración relativa de colágeno y al contenido de colágeno puro, los más utilizados son, básicamente, el grado de concentración relativa de carbono en el colágeno gelatinizado -expresado en $\% \mathrm{C}-$; la relación carbono-nitrógeno $-\mathrm{C}$ : $\mathrm{N}$ ratio-; y la ratio delta del Carbono $13-\delta 13 C-($ van Klinken 1999). En fechas más recientes, se ha propuesto que la evaluación del porcentaje de nitrógeno conservado $(\% \mathrm{~N})$ constituye un método efectivo para estimar la calidad del colágeno de las muestras óseas, antes de proceder a la datación (Brock et al. 2010; 2012).

En la actualidad Beta Analytic incluye estos parámetros en sus informes sobre dataciones de muestras óseas, si bien se trata de una política adoptada por el laboratorio en fecha reciente. Con excepción de la ratio ${ }^{13} \mathrm{C} /{ }^{12} \mathrm{C}-\delta 13 \mathrm{C}-$, que sí era incluida en los informes de 2008 , los valores de \%C y C:N de las muestras que se enviaron entonces a datar nos son hoy desconocidos.

Puestos en contacto con Beta Analytic para reclamar esta información y sugerir, de no hallarse, la realización de nuevos análisis sobre remanentes de las muestras enviadas, la respuesta del laboratorio fue que ni existía registro ni tampoco se conservaba material sobrante para poder obtener estos datos en la actualidad. Por otra parte, ninguna de ellas fue sometida a ultrafiltrado, procedimiento que por entonces ni este ni la 
Tabla 1. Dataciones mencionadas en el texto, obtenidas para las tumbas 1 y 3 y para la capa V del sector B del corte 11, según el programa OxCal v.4.3.2.

\begin{tabular}{|c|c|c|c|c|c|c|c|c|c|}
\hline Context & $\begin{array}{l}\text { ID-sam- } \\
\text { ple }\end{array}$ & Sample & Description & $\begin{array}{l}\text { Id-Labora- } \\
\text { tory }\end{array}$ & Date BP & $\begin{array}{c}13 \mathrm{C} / 12 \mathrm{C} \\
\text { ratio }(\delta 13)\end{array}$ & $\begin{array}{l}\mathrm{C}: \mathrm{N} \\
\text { ratio }\end{array}$ & $\% \mathrm{C}$ & $\% \mathrm{~N}$ \\
\hline Tumba 1 & $\begin{array}{l}\text { TA-88- } \\
\text { C11-2 }\end{array}$ & Hueso humano & $\begin{array}{l}\text { peroné dcho. }(49,4 \\
\text { g) }\end{array}$ & Beta-240410 & $3340 \pm 40$ & $-19,30 / 00$ & - & - & \\
\hline Tumba 1 & $\begin{array}{l}\text { TA-88- } \\
\text { C11-1 }\end{array}$ & $\begin{array}{l}\text { Hueso animal } \\
\text { (Ovis a/.Capra h.) }\end{array}$ & $\begin{array}{l}\text { radio-ulna dcho. } \\
(23,9 \mathrm{~g})\end{array}$ & Beta-240409 & $3380 \pm 40$ & $-19,00 / 00$ & - & - & - \\
\hline Tumba 3 & $\begin{array}{l}\text { TA-88- } \\
\text { C10-4 }\end{array}$ & Hueso humano & fémur (44 g) & KIA-38217 & $3555 \pm 25$ & $-19,50 / 00$ & - & - & - \\
\hline Tumba 3 & $\begin{array}{l}\text { TA-88- } \\
\text { C10-4 }\end{array}$ & Hueso humano & fémur (44 g) & KIA-52119 & $3570 \pm 30$ & $-18,80 / 00$ & - & 42,02 & - \\
\hline Corte 11 & TA-05 & $\begin{array}{l}\text { Hueso animal } \\
\text { (Bos t.) }\end{array}$ & falange $(26,16 \mathrm{~g})$ & Beta -487171 & $3680 \pm 30$ & $-19,50 / 00$ & 3,2 & 39,88 & 14,59 \\
\hline
\end{tabular}

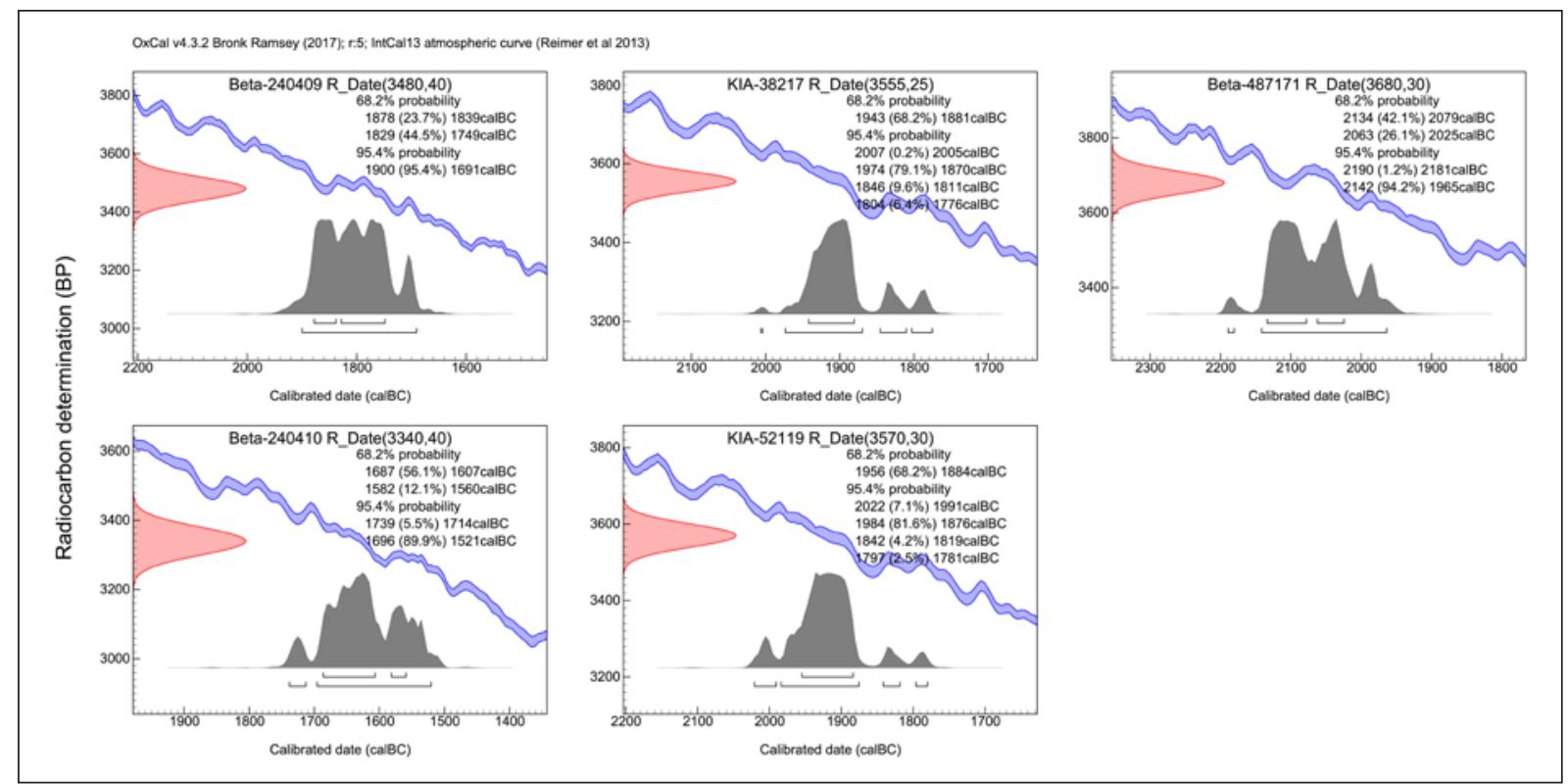

Figura 6. Gráficas de las dataciones mencionadas en el texto, obtenidas para las tumbas 1 y 3 y para la capa V del sector B del corte 11, según el programa OxCal v.4.3.2.

inmensa mayoría de laboratorios aplicaba a ningún tipo de muestra ósea. De hecho, el ultrafiltrado no ha sido aplicado al tratamiento de ninguna de las muestras datadas del Tabayá: ni a las realizadas en 2008 y 2018 por Beta Analytic ni tampoco a las que se remitieron a Kiel en 2009 y 2017.

En cualquier caso, como vía alternativa para contrastar la hipótesis de la contaminación del colágeno de los huesos de la tumba 1 , se procedió a seleccionar una muestra del esqueleto de la tumba 3 -cuya posición estratigráfica permitía asegurar su posterioridad temporal con respecto a la tumba 1- para su datación en el Leibniz-Labor für Altersbestimmung und Isotopenforschung de Kiel, en Alemania. Esta sepultura era una tumba en fosa, cuyos límites en planta no fue posible determinar con claridad durante el proceso de excavación (fig. 4.C). En su interior se depositó el cuerpo de un hombre adulto recostado sobre su lado derecho, en posición muy encogida, con los brazos flexionados y las manos frente al rostro, con los restos de una pata 
delantera de conejo como único ajuar, y un molino en posición invertida colocado sobre su cráneo, aunque sin llegar a entrar en contacto directo con él. Según el estudio de M. P. de Miguel (2004: 265) -corresponde al individuo $\mathrm{n}^{\circ} 6$ de su inventario- se trata de un individuo de aproximadamente 1,67 $\mathrm{m}$ de altura, con artrosis en la articulación costal y ciertas patologías bucales.

La muestra extraída a este esqueleto fue remitida a mediados de enero de 2009 al laboratorio de la Universidad de Kiel junto con una nueva muestra del esqueleto humano de la tumba 1, con la esperanza de obtener una segunda datación que permitiera contrastar el resultado de la datación Beta-240410. En esta ocasión se seleccionaron dos fragmentos de fémur: uno de 44 gr de peso -muestra TA88-C10-4- del esqueleto de la tumba 3 y otro de $39 \mathrm{gr}-$ muestra TA88-C11-3- del esqueleto de la tumba 1.

El informe con los resultados fue redactado a finales de julio de 2009, y en él quedaba nuevamente de manifiesto que la muestra procedente de la tumba 1 no ofrecía la cantidad suficiente de colágeno para proceder a su datación. En cambio, la de la tumba 3 había podido ser datada sin mayores problemas, si bien planteaba, como sospechábamos, un conflicto con las fechas proporcionadas por Beta Analytic para la tumba 1 -estratigráficamente anterior a la tumba $3-$, ya que la fecha KIA-38217 precedía a éstas en casi dos siglos.

Este nuevo fracaso en la datación de la muestra ósea de la tumba 1 parecía confirmar que, en efecto, nos hallábamos desgraciadamente ante un caso de mala conservación del colágeno de los huesos contenidos en la sepultura, aspecto que, como han señalado diversos autores, suele estar relacionado con altos niveles de contaminación que generalmente se revelan también en valores anómalos en el \%C, C:N y $\delta 13 \mathrm{C}$ (Ambrose 1990: 447; van Klinken 1999: 689). Por tanto, las fechas Beta-240409 y Beta-240410 debían rechazarse definitivamente como referencias cronológicas para la tumba 1 , y tomar en cambio la fecha KIA-38217 de la tumba 3 como terminus ante quem para aquella.

Sin embargo, acontecimientos posteriores arrojaron otras sombras de duda sobre la validez de dicha datación, a raíz de descubrirse que el laboratorio de Kiel había estado proporcionando fechas anómalas -junto con otras correctas- desde aproximadamente el mes de julio de 2009 hasta agosto de 2011, posiblemente a causa de un problema de contaminación en sus aparatos o en el protocolo de tratamiento de las muestras (Lull et al. 2015). De hecho, otros proyectos de investigación ligados al Museo Arqueológico de Alicante-MARQ se vieron afectados por este problema. En concreto, en 2010 , se envió a Kiel una muestra de hueso humano procedente de la tumba 13 del yacimiento bajomedieval de la Pobla de Ifach, en Calpe (Alicante), cuya fundación y duración están firmemente documentados entre finales del siglo XIII y los inicios del XV, tanto por las fuentes escritas como por el registro arqueológico. Sin embargo, la fecha proporcionada por el laboratorio KIA-42678- atribuía a la muestra IF-09/T13/3119-1 una antigüedad del $132-326$ cal AD, por lo que esta fecha, que permanece inédita, fue rechazada.

Aunque la datación KIA-38217 no se encontraba incluida en el grupo de dataciones presumiblemente afectadas por contaminación - que se consideró abarcaría, aproximadamente, desde KIA-39260 hasta KIA44844-, en junio de 2017 aceptamos el ofrecimiento del propio laboratorio para repetir la datación a partir de material sobrante de la muestra TA-88-C10-4, con el fin de confirmar la fecha proporcionada inicialmente. Se trató de una iniciativa planteada por el Dr. Roberto Risch, de la Universidad Autónoma de Barcelona, que sirvió además de interlocutor con el Dr. Christian Hamann, del Leibniz-Labor für Altersbestimmung und Isotopenforschung de la Universidad de Kiel, donde se repitió la datación de la muestra.

Por fin, el resultado de esta segunda datación, plenamente coherente con la anterior, permite fijar la fecha más probable para la tumba 3 en el intervalo 1970 1880 cal BC, consolidando de este modo el horizonte cronológico de 1900 cal BC como terminus ante quem para la tumba 1 y su ajuar funerario (fig. 7).

\section{CONSIDERACIONES EN TORNO A LA CRONOLOGÍA DE LA TUMBA 1 DEL TABAYÁ}

Así pues, en el caso del Tabayá, la única datación válida disponible hasta ahora, procedente de la tumba 3 , ha permitido situar una imprescindible referencia temporal en la secuencia de ocupación argárica del asentamiento, si bien para ello ha sido necesario, primero, descartar dos dataciones corroborando la contaminación del colágeno del que fueron obtenidas; y segundo, confirmar su validez repitiendo el procedimiento de datación a partir de la misma muestra.

Es de esperar que en un futuro próximo podamos contar con un número mayor de dataciones de los enterramientos argáricos del Tabayá, pues forma parte de los objetivos marcados para la publicación de la memoria definitiva de los trabajos. Mientras tanto, la fecha de la tumba 3 -valor combinado de KIA-38217 y KIA52119- posibilita comenzar a consolidar la estimación 


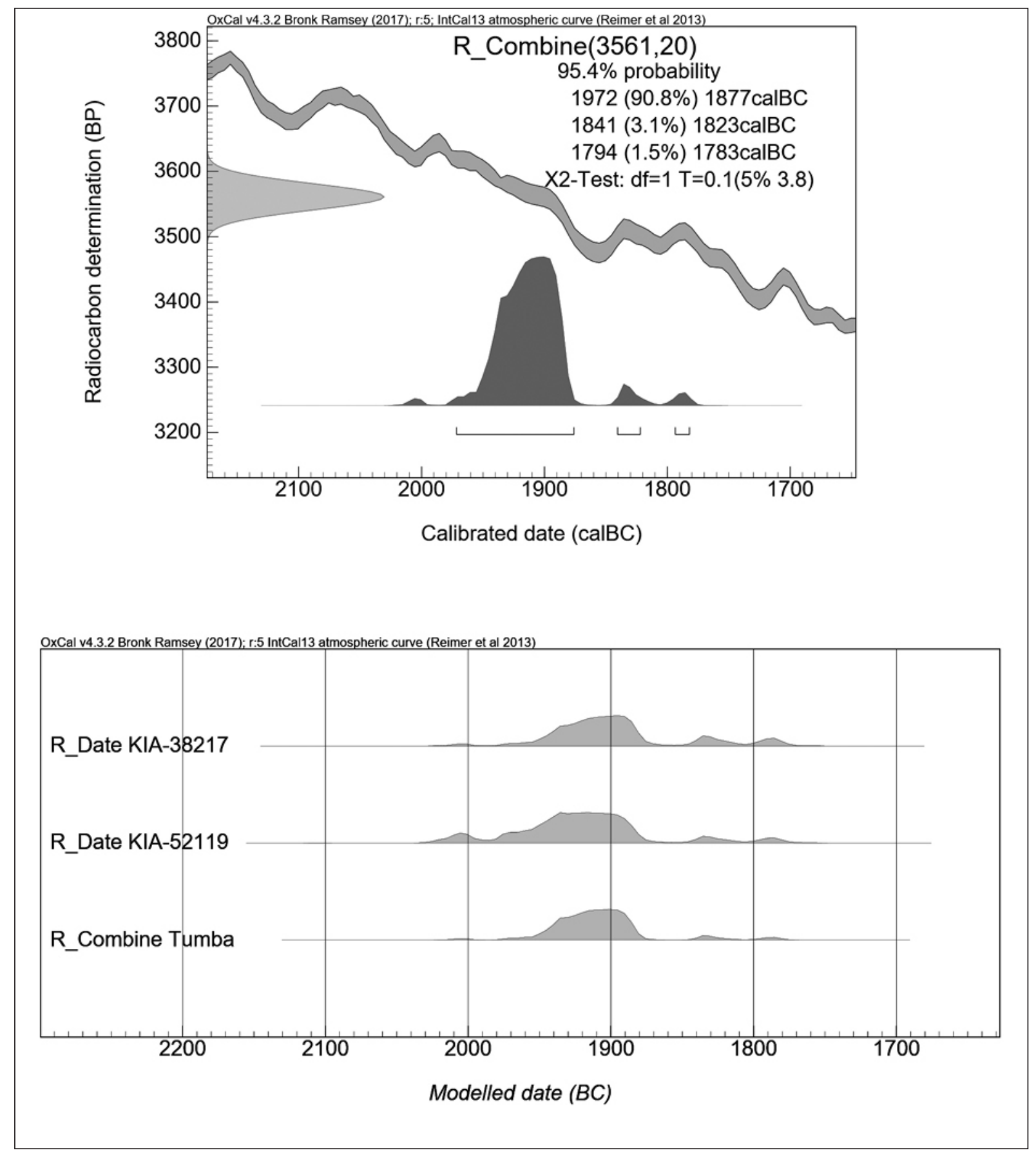

Figura 7. Calibración combinada de las dataciones KIA-38217 y KIA-52119, procedentes de la tumba 3, según el programa OxCal v.4.3.2.

que en lo temporal podemos atribuir a la estratigrafía de la fase II del yacimiento, en la que se concentran las evidencias más claramente vinculadas con el registro material argárico y a la que pertenece el que continúa siendo su conjunto funerario más relevante: la tumba 1.
Dado que ha resultado imposible obtener una datación válida de este último enterramiento, para la estimación de su cronología debemos acudir al registro estratigráfico tomando como referencia la posición que ocupa en este la tumba 3 (fig. 8), tal y como ya 


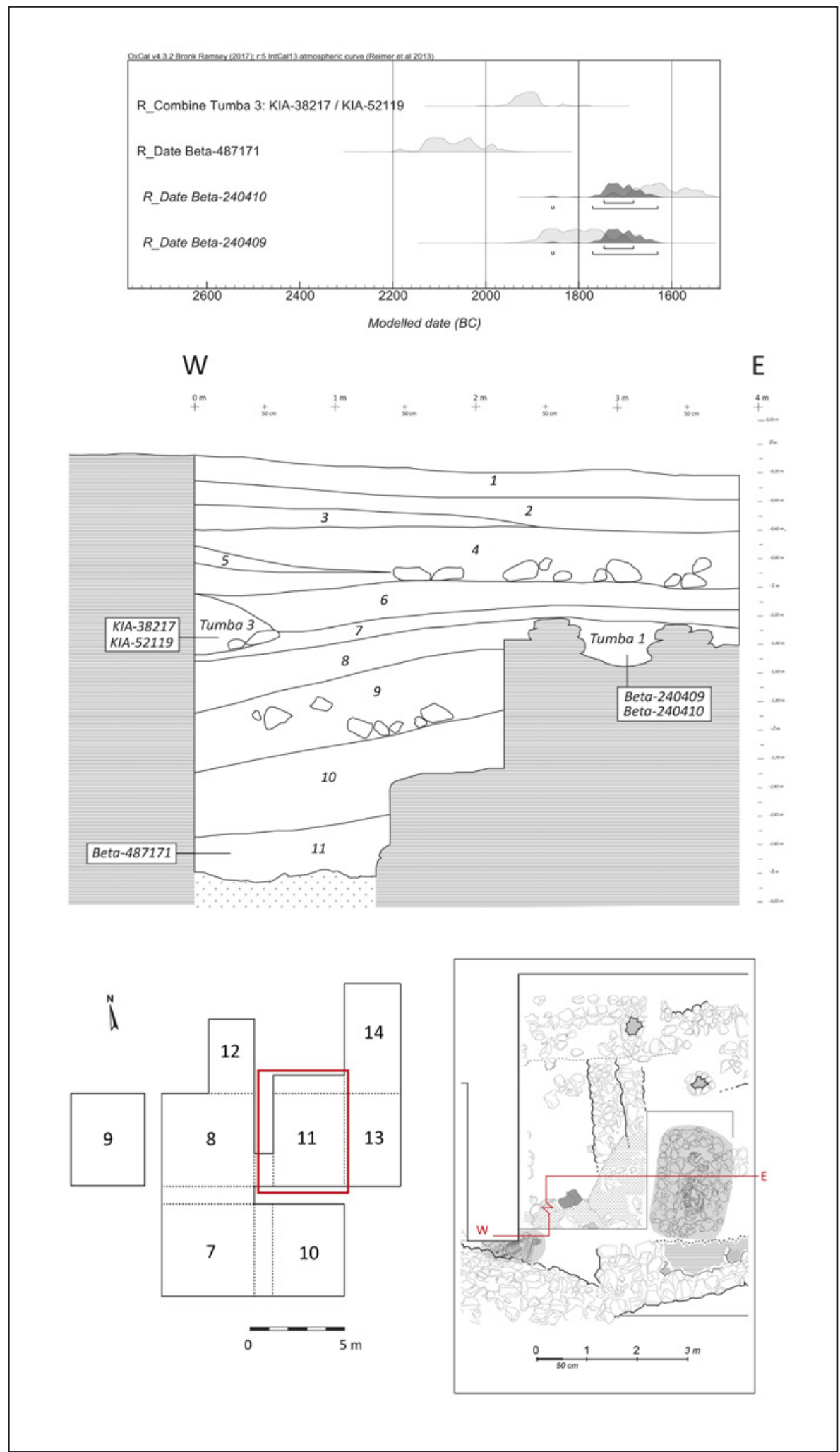

Figura 8. Sección E-O del Corte 11, con la posición relativa de las tumbas 1 y 3 en la secuencia sedimentaria documentada. 
Figura 9. Imagen de la tumba 3 en el momento de su localización, en el que puede apreciarse su posición estratigráfica relativa con respecto al muro-terraza (a la izquierda) y los restos de la madera que debió utilizarse para el cerramiento de la fosa.

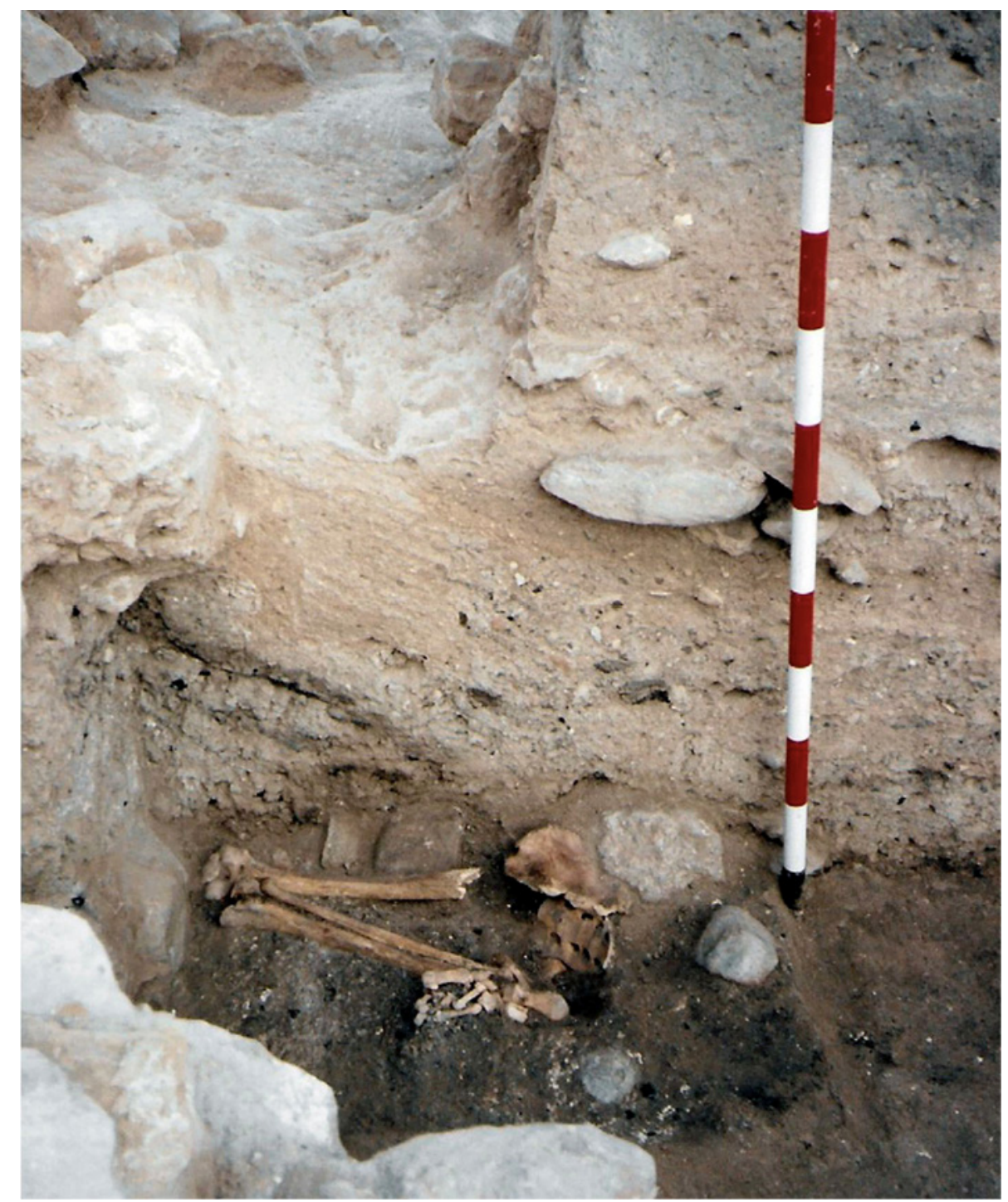

se ha señalado en diversas ocasiones (López Padilla 2009; Hernández y López 2010), especialmente ahora que la nueva datación KIA-52119 ha confirmado su datación inicial.

La tumba 3 -un enterramiento en fosa- empleó la cara septentrional de un largo muro de algo más de $10 \mathrm{~m}$ de longitud, con una marcada orientación esteoeste, que sirvió como divisoria de dos unidades habitacionales, si bien ambas posicionadas a diferente cota, de modo que dicho muro hacía también las veces de paramento para aterrazar y nivelar los pavimentos de la habitación occidental. De hecho, la cara oriental de la estructura ofrecía un aspecto claramente ataludado. El esqueleto de la tumba 3 aparecía apoyado en parte sobre la zona basal de este muro-terraza, apoyando las rodillas y la mano izquierda sobre el mampuesto (ver fig. 4.C). Aunque los límites de la fosa no pudieron identificarse con claridad, podemos deducir aproximadamente la profundidad a la que se encontraba el nivel de piso desde el que fue excavada a partir de la cota a la que se halló el molino de mano que debió formar parte de la cubierta del enterramiento. De la observación detenida del perfil oriental del corte 11 se puede deducir que el resto de la cubierta debió estar formado por tablones de madera dispuestos de forma oblicua, apoyados en la pared y fijados al suelo de la fosa en algunos bloques que aún podían apreciarse detrás de la pelvis del esqueleto en el momento del hallazgo (fig. 9).

A diferencia de la tumba 3, la tumba 1 se documentó claramente por debajo de los niveles de piso 


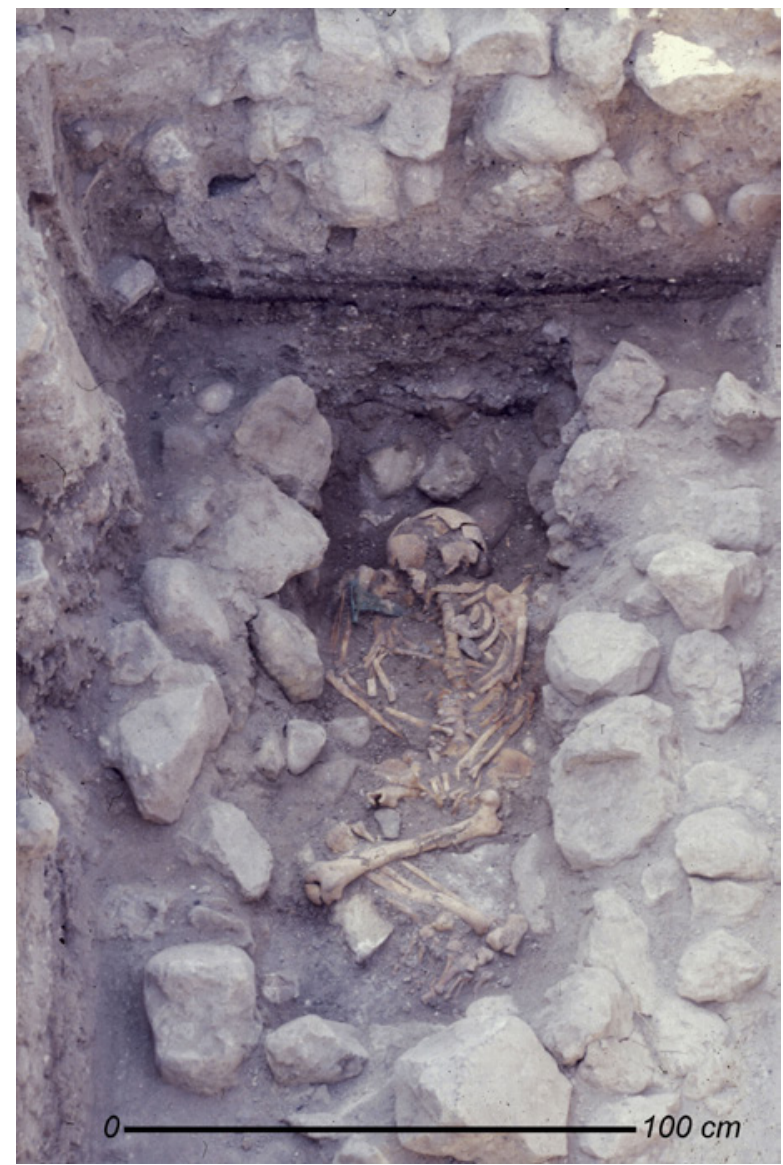

Figura 10. Vista de la cista de mampostería de la tumba 1, tras su excavación. En la parte superior de la imagen puede apreciarse la parte basal del muro de mampostería $\mathrm{y}$, por debajo del mismo, los niveles de piso infrapuestos a este y que cubrían la sepultura.

asociados al muro ataludado (fig. 10). La estratigrafía del perfil occidental del corte 11 mostraba cómo los bloques basales del muro de aterrazamiento descansaban sobre un paquete sedimentario integrado por varios pisos o suelos de nivelación de aspecto negruzco, con un abundante contenido en materia orgánica -carbones y cenizas- que, probablemente, se dispusieron sobre la cista de enterramiento una vez esta fue clausurada. En este sentido, es importante señalar que en varias de las cistas de mampostería del Tabayá pudo observarse cómo la zona del paquete sedimentario inmediatamente superpuesto a ellas aparecía dislocado y disgregado, a causa del colapso de las cubiertas - por ejemplo, en las tumbas 4 y 5 -. Por este motivo estos pavimentos no pudieron documentarse adecuadamente en la superficie del corte bajo la que se encontraba ubicada la tumba 1 , pero sí en el perfil contiguo. Por consiguiente, tanto la cista de la tumba 1 como los pavimentos inmediatamente superpuestos guardan una relación de anterioridad con respecto a la construcción del muro de aterrazamiento, al pie del cual, y aprovechando parte de su cara oriental, se excavó la fosa de enterramiento de la tumba 3, para la cual, de acuerdo con los datos proporcionados por las dataciones radiocarbónicas, podemos estimar una fecha en el intervalo 1970-1880 cal BC.

La cronología que todo ello apunta para la tumba 1 resulta, por otra parte, coherente con el periodo de vigencia estimado recientemente para las alabardas halladas en enterramientos argáricos, a partir de dataciones radiocarbónicas, que se ha fijado aproximadamente entre 2000-1800 cal BC (Lull et al. 2017a: 150, fig. 3). Sin embargo, también contribuiría a retrotraer la cronología de este tipo de alabardas con amplia placa de enmangue -el tipo I establecido por V. Lull (1983: 192-200)- al inicio de dicho intervalo, tal y como han propuesto diversos autores (Ulreich 1993-1994; Brandherm 2003). A juicio de V. Lull y otros (2017a: 152) el tipo I, sin embargo, debería continuar considerándose el tipo de alabarda más reciente, a pesar de que dicha propuesta no cuenta, por ahora, con el suficiente respaldo estadístico.

Llegados a este punto éramos plenamente conscientes de las repercusiones que, en este y en otros aspectos, podría tener la posición fijada para la tumba 1 en la secuencia temporal de ocupación del Tabayá. Por muy fundadas que pudieran considerarse las bases estratigráficas desde las que defender para ella una fecha en torno a c. 2000-1950 cal BC, y dada la imposibilidad de obtener una fecha directa válida del enterramiento, resultaba indispensable obtener al menos una referencia radiocarbónica para la parte inicial de la secuencia estratigráfica del yacimiento, con la que fijar un hito cronológico post quem para la propia tumba 1. Para ello, seleccionamos una muestra de vida corta -un fragmento de falange de Bos taurus de 26,16 gr de peso- proveniente de los estratos de colmatación que cubrían los niveles de ocupación inicial del asentamiento -concretamente, de la capa V del sector B1 del Corte 11, en la terraza inferior-, los mismos de los que procedían algunos de los fragmentos de cerámicas decoradas con incisiones y puntillados, de tradición “epicampaniforme", localizados en los contextos fundacionales del yacimiento (Hernández 1997: 102). La muestra en cuestión -TA-05- ha proporcionado, como sospechábamos, una fecha que se aviene perfectamente a la horquilla cronológica en la que se sitúa 
la etapa inicial de la Edad del Bronce en esta zona. La fecha obtenida -Beta-487171- se sitúa en $3680 \pm$ $30 \mathrm{BP}$, lo que indica un intervalo a $2 \sigma$ de 2190-1965 cal BC, si bien el mayor porcentaje de probabilidad se enmarca aproximadamente entre $c$ 2130-2010 cal BC (figs. 6 y 8).

Si consideramos la posición estratigráfica en la que se encuentra la tumba 1 con respecto a los contextos datados de la tumba 3 y de la capa $\mathrm{V}$ del Corte 11 ( ver fig. $8)$, parece razonable atribuir, pues, a aquella una cronología en torno a 2000-1950 cal BC, y situarla, en suma, hacia el final de la primera etapa de ocupación argárica del asentamiento, previa a la remodelación urbanística de la terraza inferior, con la que se relaciona la construcción del muro en el que descansan los estratos en los que se excavó la fosa de la tumba 3.

\section{CONCLUSIONES}

En las últimas décadas estamos asistiendo a una auténtica "revolución" del radiocarbono en el campo de la investigación arqueológica en general, y de la prehistoria de la península ibérica, en particular. Entre sus causas podríamos mencionar no solo el crecimiento exponencial del número de dataciones realizadas - que la generalización del uso de la técnica de AMS y el considerable abaratamiento de sus costes económicos han propiciado-, sino también el perfeccionamiento de los procedimientos de manejo y análisis de las muestras y las mejoras que ha supuesto, para una interpretación más correcta de las fechas, la aplicación de modelos estadísticos bayesianos. Todo ello está suponiendo un considerable avance en la precisión cronológica de la ocupación de los yacimientos (Lull et al. 2013; Aranda y Lozano 2014, entre otros) y en el desarrollo de propuestas de periodización más ajustadas a la realidad (Jover, López y García-Donato 2014).

Al compás de estos cambios, no hace mucho sugeríamos el abandono definitivo de ciertas rutinas de trabajo, predominantes en la investigación durante el siglo pasado -y aún vigentes en algunos entornos académicos de nuestro país-, que no permiten garantizar la representatividad de las muestras datadas en relación con los eventos a los que se otorga una significación histórica, conservados en las secuencias estratigráficas de los yacimientos (Jover y López 2011). El absoluto predominio de las muestras de vida corta en la elaboración de las últimas series radiocarbónicas publicadas en el Este y Sureste de la península ibérica, y la concluyente implantación de los modelos estadísticos bayesianos en la lectura e interpretación de los datos, parecen mostrar que dichas rutinas formarán ya pronto parte del pasado (Bayliss et al. 2016; Aranda et al. 2017).

Como caso de estudio, en este trabajo han sido expuestas las circunstancias que han rodeado la aportación, hace algo más de una década, de dos fechas radiocarbónicas por parte de un laboratorio que en ningún momento se desdijo de la validez de las mismas, a pesar de que se mostraban contradictorias no solo entre sí, sino también con las referencias estratigráficas de las muestras de las que se obtuvieron. Hemos descrito el largo periplo seguido a lo largo de estos diez años para tratar de resolver tales contradicciones, y apuntado solo algunas de las implicaciones que ello ha podido tener para la correcta representación de los procesos históricos que, como científicos sociales, estamos dedicados a explicar y comprender: en nuestro caso, la conformación y desarrollo de la sociedad argárica en el extremo oriental del Sureste peninsular.

La datación radiocarbónica debe dejar, por fin, de constituir el eje principal del discurso cronológico y pasar a ocupar el lugar que le corresponde en el marco de la investigación: el de integrarse junto con el resto de la información arqueológica como un dato más, el cual ha de mostrarse en coherencia con todo el conjunto registrado en un yacimiento. La consecuencia lógica de este cambio de status en la valoración de las dataciones radiocarbónicas ha sido su cuestionamiento: la evaluación crítica de la calidad de las muestras que proporcionan las dataciones y de los procedimientos seguidos por los laboratorios (Lull et al. 2015) y la exploración de los propios límites de la herramienta (Lull et al. 2017a), todo lo cual resultaría imposible sin una minuciosa y exhaustiva documentación y análisis de las estratigrafías y de los contextos de los que las muestras datadas provienen.

\section{Agradecimientos}

Queremos expresar nuestro agradecimiento a Christian Hamann, del Leibniz-Labor für Altersbestimmung und Isotopenforschung de la Universidad de Kiel, por prestarse desinteresadamente a la repetición de la datación de la muestra TA-88-C10-4, y a Roberto Risch, de la Universidad Autónoma de Barcelona, habernos servido el contacto. También queremos agradecer a José L. Menéndez, del Museo Arqueológico de Alicante-MARQ, habernos facilitado los datos inéditos de la datación KIA-42678. También queremos agradecer a los evaluadores anónimos y revisores de este trabajo todas sus 
apreciaciones y sugerencias, que, sin duda, han servido para mejorar ostensiblemente su versión final.

El presente trabajo ha sido realizado en el marco del proyecto de investigación "Espacios sociales y espacios de frontera durante el Calcolítico y la Edad del Bronce en el Levante de la península ibérica" (HAR201676586-P), financiado por el Ministerio de Economía y Competitividad del Gobierno de España.

\section{BIBLIOGRAFÍA}

Ambrose, S.H. (1990): "Preparation and characterization of bone and tooth collagen for isotopic analysis". Journal of Archaeological Science 17: 431-451. DOI: https://doi.org/10.1016/0305-4403(90)90007-R

Aranda Jiménez, G. y Lozano Medina, A. (2014): “The chronology of megalithic funerary practices: a bayesian approach to Grave 11 at El Barraquete necrópolis (Almería, Spain)". Journal of Archaeological Science 50: 369-382. DOI: https://doi. org/10.1016/j.jas.2014.08.005

Aranda Jiménez, G.; Montón Subías, S. y Sánchez Romero, M. (2015): The Archaeology of Bronze Age Iberia: Argaric Societies. Londres y Nueva York, Routlegde.

Aranda Jiménez, G.; Lozano Medina, A.; Sánchez Romero, M.; Díaz-Zorita Bonilla, M. y Bocherens, H. (2017): “Chronology of Megalithic funerary practices in Southeastern Iberia: The necrópolis of Panoria (Granada, Spain)". Radiocarbon 2017: 1-19. DOI: https://doi.org/10.1017/RDC.2017.96

Badal García, E. (1990): “Análisis anatómico de un fragmento de madera del yacimiento arqueológico del Tabayá (Aspe, Alicante)", en Homenaje a Jerónimo Molina:, pp. 95-97. Murcia, Alfonso X el Sabio.

Barciela González, V. (2016): El lenguaje de los adornos: tecnología, uso, y función. Adornos personales de la Edad del Bronce en Alicante y Albacete. Tesis doctoral. Universidad de Alicante. Disponible en: http://hdl.handle.net/10045/53182. [Consulta: 19/02/2018].

Bayliss, A. (2009): "Rolling out revolution: using radiocarbon dating in archaeology". Radiocarbon 51, 1: 123-147. DOI: https://doi.org/10.1017/ S0033822200033750

Bayliss, A.; Beavan, N.; Bronk Ramsey, C.; DelgadoHuertas, A.; Díaz-Zorita Bonilla, M.; Dunbar, E.; Fernández-Flores, A.; García Sanjuán, L.; Hamilton, D.; Mora-González, A. y Whittle, A. (2016): "La cronología radiocarbónica del tholos de Montelirio”, en A.
Fernández Flores, L. García Sanjuán, M. Díaz-Zorita Bonilla, (eds), Montelirio. Un gran monumento megalitico de la Edad del Cobre:, pp. 482-502. Sevilla, Consejería de Cultura de la Junta de Andalucía.

Belmonte Mas, D. (2004): “Un conjunto cerámico del Bronce Tardío e inicios del Bronce Final del yacimiento del Tabayá (Aspe, Alicante). Excavaciones arqueológicas de 1987 a 1991 . Corte estratigráfico n 11 ”, en L. Hernández, L. y M. S. Hernández M.S. (eds.), La Edad del Bronce en las tierras valencianas y zonas limitrofes:, pp. 333-345. Alicante, Instituto de Cultura Juan Gil-Albert.

Bernabeu Aubán, J. (1984): El vaso campanifome en el País Valenciano. Serie Trabajos Varios 80. Valencia, Servicio de Investigación Prehistórica, Diputación Provincial.

Brandherm, D. (2003): Die Dolche und Stabdolche der Steinkupfer-und der älteren Bronzezeit auf der Iberischen Halbinsel. Prähistorische Bronzefunde VI (12). Stuttgart, Steiner Verlag.

Brock, F.; Higham, Th.; Ditchfield, P. y Bronk Ramsey, C. (2010): "Current pretreatment methods for AMS radiocarbon dating at the Oxford Radiocarbon Accelerator Unit (ORAU)". Radiocarbon 52, 1: 103-112. DOI: https://doi.org/10.1017/ S0033822200045069

Bronk Ramsey, C.; Higham, Th.; Bowles, A. y Hedges R. (2004): "Improvements to the pretreatment of bone at Oxford". Radiocarbon 46(1): 155-163. DOI: https://doi.org/10.1017/S0033822200039473

Bronk Ramsey, C. (1994): “Analysis of Chronological Information and Radiocarbon Calibration: the program OxCal". Archaeological Computing Newsletter 41: 11-16.

Bronk Ramsey, C. (1995): "Radiocarbon Calibration and Analysis of Stratigraphy: The OxCal Program". Radiocarbon 37(2): 425-430. DOI: https://doi. org/10.1017/S0033822200030903

Bronk Ramsey, C. (2001): "Development of the Radiocarbon Program OxCal". Radiocarbon 43, 2A: 355-363. DOI: https://doi.org/10.1017/ S0033822200038212

Bronk Ramsey, C. (2009): "Bayesian analysis of radiocarbon dates". Radiocarbon 51, 1: 337-360. DOI: https://doi.org/10.1017/S0033822200033865

Buck, C.E. (2004): "Bayesian chronological data interpretation: where now?", en C. E. Buck, C.E. y A. R. Millard A.R. (eds.), Tools for Constructing Chronologies. Lecture Notes in Statistics, vol 177: pp. 1-24. Springer, London. DOI: https://doi. org/10.1007/978-1-4471-0231-1 1 
Buck, C.E.; Cavanagh, W.G. y Litton, C.D. (1996): The Bayesian approach to interpreting archeological data. Chichester, Wiley and Sons.

Buck, C.E.; Christen, J.A. y James, G.N. (1999): "Bcal: an on-line Bayesian radiocarbon calibration tool". Internet archaeology 7 (http: intarch. ac.uk/journal/issue7/buck/). DOI: https://doi. org/10.11141/ia.7.1

Castro Martínez, P. V.; Lull, V. y Micó, R. (1996): Cronología de la Prehistoria Reciente de la Península Ibérica y Baleares (c. 2800-900 cal ANE). B.A.R. International Series 652. Oxford, Archaeopress.

Colominas Roca, J. (1936): "La necròpolis de "Las Laderas del Castillo" (Callosa de Segura, província d'Alacant". Anuari del Institut d'Estudis Catalans VIII: $33-41$.

De Miguel Ibañez, Mª P. (2003): “Aspectos antropológicos y paleopatológicos de las inhumaciones prehistóricas del Tabayá (Aspe, Alicante)", en Actas del VI Congreso Nacional de Paleopatología: 263278. Madrid, Universidad Autónoma.

Gilman, A. (2003): "El impacto del radiocarbono sobre el estudio de la Prehistoria tardía de la Península Ibérica: breves comentarios". Trabajos de Prehistoria 60, 2: 7-13. DOI: http://dx.doi.org/10.3989/ tp.2003.v60.i2

González Marcén, P. (1994): “Cronología del grupo argárico". Revista d'Arqueologia de Ponent 4: 7-46.

González Prats, A. (1986): "La Peña Negra V. Excavaciones en el poblado del Bronce Antiguo y en el recinto fortificado ibérico (Campaña de 1982)". Noticiario Arqueológico Hispánico 27: 145-263.

Hedges, R.E.M.; Housley, R. A.; Ramsey C. B. y Klinken, G. J. (1995): "Radiocarbon dates from the Oxford AMS System: Archaeometry Datelist 20". Archaeometry 37, 2: 417-430. DOI: https://doi. org/10.1111/j.1475-4754.1995.tb00754.x

Hernández Pérez, M.S. (1982): “Cueva de la Casa Colorá: un yacimiento eneolítico en el Valle Medio del Vinalopó (Alicante)". Lucentum I: 5-18. DOI: http://dx.doi.org/10.14198/LVCENTVM1982.1.01

Hernández Pérez, M.S. (1983): "La metalurgia prehistórica en el Valle Medio del río Vinalopó". Lucentum II: 17-42. DOI: http://dx.doi.org/10.14198/LVCENTVM1983.2.02

Hernández Pérez, M.S. (1986): "La Cultura del Argar en Alicante. Relaciones temporales y espaciales con el mundo del Bronce Valenciano", en Homenaje a Luis Siret: pp. 341-350. Sevilla, Conserjería de Cultura, Junta de Andalucía.
Hernández Pérez, M.S. (1990): “Un enterramiento argárico en Alicante", en Homenaje a Jerónimo Molina:, pp. 87-94. Murcia, Alfonso X el Sabio.

Hernández Pérez, M.S. (1997): "Desde la periferia de El Argar. La Edad del Bronce en las tierras meridionales valencianas". Saguntum 30: 93-114. DOI: https://doi.org/10.7203/SAGVNTVM..2131

Hernández Pérez, M.S. (2009): "Entre el Medio y Bajo Vinalopó. Excavaciones arqueológicas en el Tabayá (Aspe, Alicante) 1987-1991”, en M.S. Hernández, M.S.; J. A. Soler, J.A. y J.A. López Padilla, J.A. (eds.), En los Confines del Argar. Una cultura de la Edad del Bronce en Alicante:, pp. 160-169. Alicante, MARQ-Museo Arqueológico de Alicante, Diputación de Alicante.

Hernández Pérez, M.S. (2012): "El Cabezo Redondo (Villena, Alicante) y el Bronce Tardío en las tierras meridionales valencianas, Cogotas I: La cultura de la Edad del Bronce en la Península Ibérica", en J.A. Rodríguez, J.A. y J. Fernández, J. (coords.), Homenaje a $M^{a}$ Dolores Fernández Posse:, pp. 111-146. Valladolid, Universidad de Valladolid.

Hernández Pérez, M.S. y López Mira, J.A. (1992): "Bronce Final en el Medio Vinalopó. A propósito de dos conjuntos cerámicos del Tabaià (Aspe, Alicante)". Trabajos Varios del SIP 89:, pp. 1-16. Valencia, Museo de Prehistoria de Valencia, Diputación Provincial.

Hernández Pérez, M.S. y López Padilla, J. A. (2010): "La muerte en el Argar alicantino. El Tabaià como paradigma", en B. Soler Mayor, B. y A. Pérez Fernández, A. (coords.), Restos de vida, restos de muerte: la muerte en la Prehistoria:, pp. 221-228. Valencia, Museo de Prehistoria de Valencia. Disponible en: http://mupreva.org/pub/314/es

Higham, T.F.G.; Jacobi, R.M. y Bronk Ramsey, C. (2006): "AMS radiocarbon dating of ancient bone using ultrafiltration”. Radiocarbon 48. 2: 179-195. DOI: https://doi.org/10.1017/S0033822200066388

Jiménez de Cisneros, D. (1910): “Excursión al Tabeyán (Alicante)". Boletín de la Sociedad Española de Historia Natural t. X, julio 1910:327-330. http://bibdigital.rjb.csic.es/ing/Libro.php?Libro=1197\&Pagina=1

Jover Maestre, F.J. y López Padilla, J.A. (1997): Arqueología de la muerte. Prácticas funerarias en los límites de El Argar. Alicante, Universidad de Alicante.

Jover Maestre, F. J. y López Padilla, J. A. (2009): “Miquel Tarradell y José María Soler: la revolución radiocarbónica y la Edad del Bronce en la península Ibérica". Pyrenae 40, 2: 79-103. 
Jover Maestre, F. J. y López Padilla, J. A. (2011): “La observación en el estudio de la edad del bronce en tierras valencianas. Del ensalzamiento del "objeto" y la revolución radiocarbónica al necesario reencuentro con la estratigrafía". Cuadernos de Prehistoria y Arqueología de Castellón 29: 209-230.

Jover Maestre, F.J.; López Padilla, J.A. y García-Donato, G. (2014): "Radiocarbono y estadística bayesiana: aportaciones a la cronología de la Edad del Bronce en el extremo oriental del Sudeste de la península Ibérica". Sagvntvm 46: 41-69. DOI: https:// dx.doi.org/10.7203/SAGVNTVM.46.3479

Jover Maestre, F.J.; Lorrio Alvarado, A. y Díaz Tena, $M^{a}$ A. (2016): "El Bronce Final en el levante de la península Ibérica: bases arqueológicas y periodización". Complutum 27, 1: 81-108. DOI: http:// dx.doi.org/10.5209/CMPL.53218

Longin, R. (1971): "New method of collagen extraction for radiocarbon dating”. Nature 230: 241-242. DOI: https://doi.org/10.1038/230241a0

López Mira, J. A. (2009): "De hilos, telares y tejidos en el Argar alicantino", en M.S. Hernández, M.S., J.A. Soler, J.A. y J.A. López Padilla, J.A. (eds.), En los Confines del Argar. Una cultura de la Edad del Bronce en Alicante:, pp. 136-153. Alicante, MARQ-Museo Arqueológico de Alicante, Diputación Provincial.

López Padilla, J. A. (2009): “El grupo argárico en los confines orientales del Argar", en M.S. Hernández Pérez, J.A. Soler Díaz y J.A. López Padilla (eds), En los Confines del Argar. Una cultura de la Edad del Bronce en Alicante, pp. 246-267, Alicante, MARQ-Museo Arqueológico de Alicante, Diputación Provincial.

López Padilla, J. A. (2011): Asta, hueso y marfil. Artefactos óseos de la Edad del Bronce en el Levante y. Sureste de la Península Ibérica (c. 2500-c. 1300 cal BC). Alicante, MARQ, Diputación Provincial.

López Padilla, J. A.; Belmonte Mas, D. y De Miguel Ibañez, M . P. (2006): "Los enterramientos argáricos de la Illeta dels Banyets de El Campello. Prácticas funerarias en la frontera oriental de El Argar", en J.A. Soler Díaz, J.A. (ed.), La ocupación prehistórica dels Banyets (El Campello):, pp. 119-171. Alicante, Museo Arqueológico Provincial de Alicante-MARQ, Diputación Provincial.

Libby, W.L. (1952): Radiocarbon dating. Chicago, University of Chicago Press.

Lull,V. (1983): La "cultural” de El Argar. Un modelo de estudio de las formaciones económico-sociales prehistóricas. Madrid, Akal Universitaria.
Lull, V.; Micó, R.; Rihuete, C. y Risch, R., (2010): “Límites históricos y limitaciones del conocimiento arqueológico: la transición entre los grupos arqueológicos de Los Millares y El Argar", en P. Bueno, P.; A. Gilman, A.; C. Martín, C. y F.J. Sánchez Palencia F.J. (eds.), Arqueología, sociedad, territorio y paisaje, Homenaje a $M^{a}$ Dolores Fernández Posse, pp. 75-94. Madrid, Universidad Complutense.

Lull, V.; Micó, R.; Rihuete, C. y Risch, R. (2013): “Funerary practices and kinship in an Early Bronze Age society: a Bayesian approach applied to the radiocarbon dating of Argaric double tombs". Journal of Archaeological Science 40/12: 4626-4634. DOI: https://doi.org/10.1016/j.jas.2013.07.008

Lull, V.; Micó, R., Rihuete Herrada C. y Risch, R. (2015) "When 14C Dates Fall Beyond the Limits of Uncertainty: An Assessment of Anomalies in Western Mediterranean Bronze Age ${ }^{14} \mathrm{C}$ Series". Radiocarbon, Vol. 57, 5: 1029-1040. DOI: https://doi. org/10.2458/azu_rc.57.18180

Lull, V.; Micó, R.; Rihuete-Herrada, C.; Risch, R. y Escanilla, N. (2017a): "The absolute chronology of Argaric halberds", en J.A. Barceló, J.A.; I. Bogdanovic, I y B. Morell, B. (eds), IberCrono 2016. Cronometrías para la Historia de la Península Ibérica. Actas del Congreso de Cronometrías para la Historia de la Península Ibérica, (Barcelona 2016), Vol-2024: 144-162. Barcelona (2016), Barcelona, CEUR Workshop Proceedings (urn:nbn:de:0074-2024-4). Disponible en http:// ceur-ws.org/Vol-2024

Lull, V.; Micó, R., Rihuete-Herrada, C.; Risch, R.; Van Strydonck, M. y Boudin, M. (2017b): "Multiple radiocarbon dating of a single skeleton. Assessing issues of precision and accuracy in the Argaric Bronze Age", en J.A. Barceló, J.A.; I. Bogdanovic, I. y B. Morell, B. (eds), IberCrono 2016. Cronometrías para la Historia de la Península Ibérica. Actas del Congreso de Cronometrías para la Historia de la Península Ibérica, (Barcelona, 2016), Vol-2014: 163-171. Barcelona (2016), Barcelona, CEUR, CEUR Workshop Proceedings (urn:nbn:de:0074-2024-4). Disponible en http://ceur-ws.org/Vol-2024

Lull, V.; Micó, R.; Rihuete-Herrada, C.; Risch, R. y Escanilla, N. (2017c): "Halberdiers and combat systems in the Argaric". Oxford Journal of Archaeology 36(4): 375-394. DOI: https://doi.org/10.1111/ ojoa. 12120

Martínez Rodríguez, A.; Ponce García, J. y Ayala Juan, M. M. (1996): Las prácticas funerarias de la 
cultura argárica en Lorca, Murcia. Lorca, Ayuntamiento de Lorca, Cajamurcia.

Martínez Rodríguez, A. y Ponce García, J. (2002): “Excavación arqueológica de urgencia en el subsuelo de la antigua Iglesia del Convento de las Madres Mercedarias (C/ Zapatería - C/ Cava, Lorca)". Memorias de Arqueología 10 (1995): 90-137. Murcia, Consejería de Educación y Cultura.

Mederos Martín, A. (1995): "La cronología absoluta de la prehistoria reciente del sureste de la Península Ibérica". Pyrenae 26: 53-90.

Millard, A. R. (2005): "What can Bayesian statistics do for archaeological predictive modelling?", en P.M. Van Leusen, P.M. y H. Kamermans, H. (eds.), Predictive modeling for archaeological heritage management: a research agenda, Nederlandse Archeologische Rapporten 29: 169-182. Amersfoort, Rijkdienst voor het Oudheidkundig Bodemonderzoek.

Molina Fajardo, F. (1978): “Definición y sistematización del Bronce Tardío y Final en el Sureste de la Península Ibérica". Cuadernos de Prehistoria y Arqueología de la Universidad de Granada 3: 159-232.

Molina Mas, F.A. (1999): “La cerámica del Bronce Tardío e inicios del Bronce Final en el Valle Medio del río Vinalopó: el ejemplo del Tabayá (Aspe, Alicante)". Revista d'Arqueologia de Ponent 9: 117-130. Disponible en: http://handle. net/10459.1/45118

Moratalla Jávega, J. (2005): “El territorio meridional de la Contestania”, en L. Abad, L.; F. Sala, F. y e I. Grau, I. (eds.), La Contestania Ibérica, treinta años después. Anejo a la revista Lucentum 13: pp. 91117. Alicante, Universidad de Alicante.

Navarro Mederos, J.F. (1982): "Materiales para el estudio de la Edad del Bronce en el Valle Medio del Vinalopó". Lucentum I: 19-70. DOI: http://dx.doi. org/10.14198/LVCENTUM1982.1.02

Renfrew, C. (1973): Before Civilization: the radiocarbon revolution and prehistoric Europe. London, Pimlico.

Reimer, P. J.; Bard, E.; Bayliss, A.; Beck, J. W.; Blackwell, P. G.; Bronk Ramsey, C.; Buck, C. E.; Cheng,
H.; Edwards, R. L.; Friedrich, M.; Grootes, P. M.; Guilderson, T. P.; Haflidason, H.; Hajdas, I.; Hatté, C.; Heaton, T. J.; Hoffmann, D. L.; Hogg, A. G.; Hughen, K. A.; Kaiser, K. F.; Kromer, B.; Manning, S. W.; Niu, M.; Reimer, R. W.; Richards, D. A.; Scott, E. M.; Southon, J. R.; Staff, R. A.; Turney, C. S. M. y Van Der Plicht, J. (2013): "IntCal13 and Marine13 Radiocarbon Age Calibration Curves 0-50,000 Years cal BP”. Radiocarbon 55, 4: 1869-1887. DOI: https://doi.org/10.2458/azu js rc.55.16947

Rizo Antón, C. (2009): Estudio arqueozoológico del Tabayá (Aspe, Alicante). Ganadería y caza durante la Edad del Bronce. Villena, Fundación Municipal "José María Soler".

Schiffer, M.B. (1986): "Radiocarbon dating ans de "old wood" problem: the case of the Hohokam chronology". Journal of Archaeological Science 13: 13-30. DOI: https://doi.org/10.116/03054403(86)90024-5

Sealy, J.; Johnson, M.; Richards, M. y Nehlich, O. (2014): "Comparison of two methods of extracting bone collagen for stable carbon and nitrogen isotope analysis: comparing whole bone demineralization with gelatinization and ultrafiltration". Journal of Archaeological Science 47: 64-69. DOI: https://doi.org/10.1016/j.jas.2014.04.011

Simón García, J. L. (1998): La metalurgia prehistórica valenciana. Serie Trabajos Varios 93. Valencia, Servicio de Investigación Prehistórica, Diputación Provincial.

Soler Díaz, J. A. (2006) (coord.): La ocupación prehistórica de la Illeta dels Banyets. Serie Mayor 5. Alicante, MARQ, Diputación Provincial.

Ulreich, H. (1993-1994): "Die zeitiche Ordnung der Stabdolchklingen aus El Argar, El Oficio und Fuente Alamo (Almeria, Spanien)". Mitteilungen der Anthropologischen Gesellschaft in Wien 123/124: 301-314.

Watson, P.J.; Leblanc, S.A. y Redman, C.L. (1971): Archaeological explanation: An explicity scientific approach. New York, Columbia University Press. 
